\title{
Inherited enzyme defects: a review
}

\author{
T. HARGREAVES ${ }^{1}$ \\ From the Department of Chemical Pathology, St. George's Hospital Medical School, \\ Hyde Park Corner, London, S.W.I
}

Sir Archibald Garrod in 1909 pointed out that four diseases, albinism, alkaptonuria, cystinuria, and pentosuria, were present from birth, lasted throughout life without worsening or improvement, and were present in other members of the family (Garrod, 1909). These diseases were described as 'inborn errors of metabolism'. The original four diseases have been expanded to over 50 and the actual site of the biochemical abnormality has been elucidated in many of them. In this review we shall consider those diseases which are either known or thought to be due to single enzyme defects. We have not considered those diseases that are thought to be due to renal tubular or intestinal abnormalities, for example, cystinuria. It is not yet known whether this type of disease is due to a specific enzyme defect.

The fundamental discovery of Mendel (1901) concerning the inheritance of plant characters had just been resurrected and given prominence at the time when Garrod was most active. The transmission of a single character as a governing agent for a single enzyme and accordingly, as one step in intermediary metabolism, seems implicit in Garrod's writings but is never stated as such. The concept attained clear definition in the 'one gene-one enzyme' principle first clearly stated by Beadle (1945). The formulation emerged gradually from studies of eye colour in the fruit fly Drosophila and received extensive support from work done on induced mutants of Neurospora crassa. The concept has been expressed as: 1 All biochemical processes in all organisms are under genic control. 2 These biochemical processes are resolvable into series of individual stepwise reactions. 3 Each biochemical reaction is under the ultimate control of a different gene. 4 Mutation of a single gene results only in an alteration in the ability of the cell to carry out a single primary chemical reaction.

It is now realized that the one gene-one enzyme concept does not require a one enzyme-one gene corollary, and that the 'gene' is being replaced by progressively smaller units of ultimate genetic control.

${ }^{1}$ B.M.A. research scholar
The consequences of a genetic change and an alteration in the quality or quantity of a protein will depend on the role normally subserved by that protein; in the cases that we are considering this is derangement of enzymatic function. The derangements that can occur include a blocked metabolic sequence. In the reaction $\mathrm{A} \longrightarrow \mathrm{B} \longrightarrow \mathrm{C} \longrightarrow \mathrm{D}$, if $\mathrm{C} \longrightarrow \mathrm{D}$ is blocked then a clinical disorder may result from a failure to produce $\mathrm{D}$, e.g., hypoglycaemia due to an inability to form glucose from glucose-6-phosphate in von Gierke's disease. The precursor $\mathrm{C}$ may accumulate; for example, bilirubin accumulates in the absence of glucuronyl transferase. The remote precursers A and B may accumulate, for example, glycogen in von Gierke's disease. The block between $C$ and $D$ may result in an increased utilization of normally minor pathways, for example, in phenylketonuria. The application of these metabolic cycles will be reviewed in each section.

The subject has been covered generally in recent reviews, for example, that of Stanbury, Wyngaarden, and Fredrickson (1960).

\section{DISTURBANCES IN AMINO-ACID METABOLISM}

Recent advances in the past few years in the understanding of the biochemistry of the amino-acids coupled with the use of amino-acid chromatography in urine has helped to elucidate problems in the disturbance of amino-acid metabolism and to demonstrate new cases of disturbed amino-acid metabolism.

PHENYLKetONURIA In 1934 Følling described 10 patients, some of them siblings, who excreted phenyl pyruvic acid and were mentally deficient. Jervis (1953) demonstrated that phenylalanine hydroxylase of the liver was inactive in these patients. The condition is inherited through a single autosomal recessive gene. It is required that both parents of a patient have the defective form of one of the two genes controlling phenylalanine hydroxylase; an apparent reduction of phenylalanine hydroxylase can be detected in the parents. On the average one 


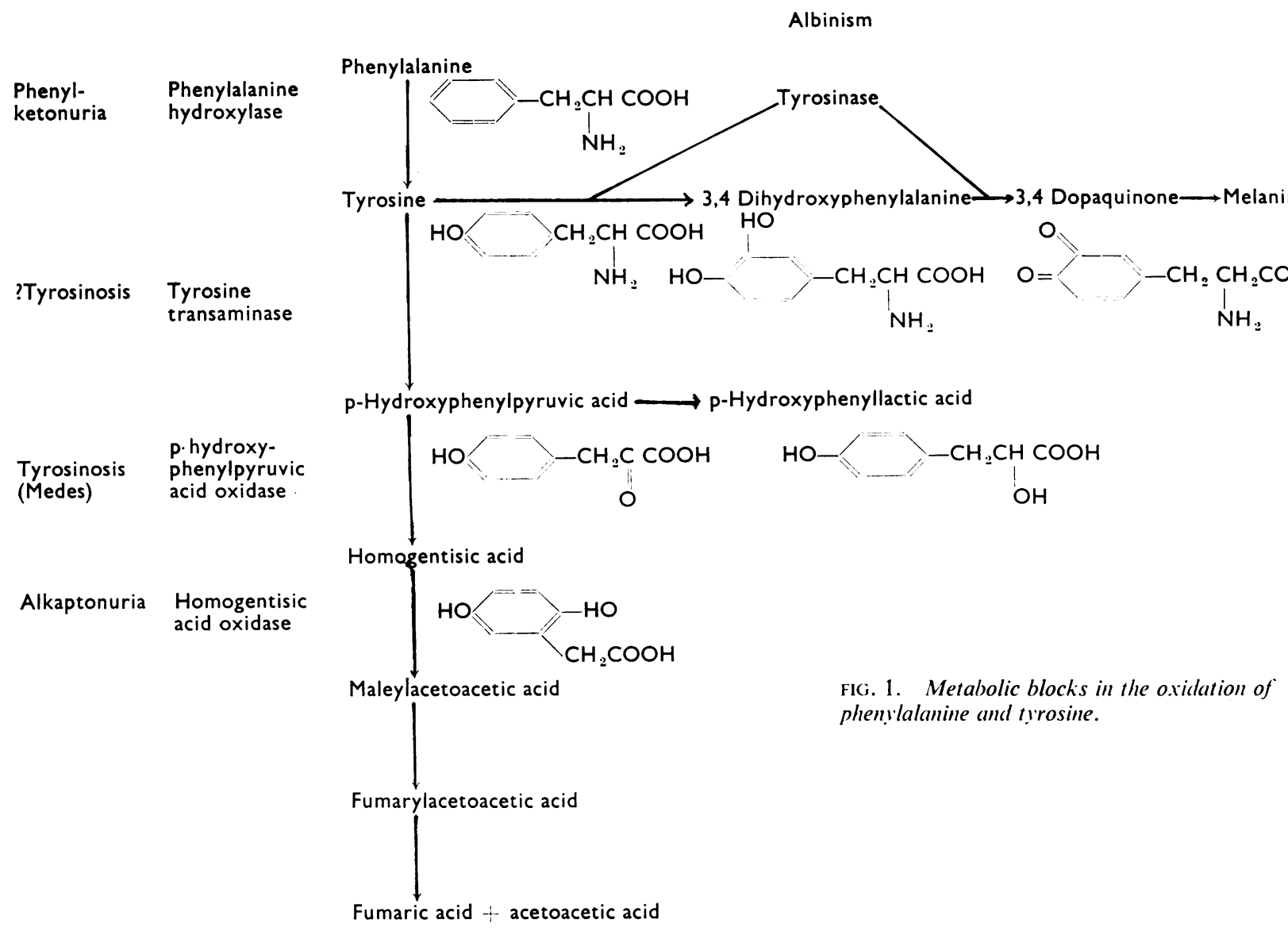

out of four offspring from two heterozygous parents has both genes defective, and in these offspring phenylketonuria results. The disability is first manifest several weeks after birth, initially by elevation of the plasma phenylalanine level and by the excretion of phenylpyruvic acid. After six months, retardation of mental development is apparent. Many of the children have blond hair, blue eyes and fair skin, and a few show a tendency to develop dermatitis or eczema. The majority of patients have an I.Q. of 30 or less.

Pathogenesis Phenylalanine is converted to tyrosine by the enzyme system 'phenylalanine hydroxylase' in the liver alone; the reaction can be represented as

$$
\begin{array}{r}
\text { L-phenylalanine }+\mathrm{O}_{2}+\text { N.A.D.P.H. }{ }^{1}+\mathrm{H}^{+}-\rightarrow \\
\text { L-tyrosine }+ \text { N.A.D.P. }{ }^{+}+\mathrm{H}_{2} \mathrm{O} .
\end{array}
$$

${ }^{1}$ The following abbreviations are used

A.T.P. Adenosine Triphosphate

N.A.D. Nicotinamide-adenine dinucleotide

N.A.D.P. Nicotinamide-adenine dinucleotide phosphate

U.D.P.G.A. Uridine diphosphate glucuronic acid

U.D.P. Uridine 5'-pyrophosphate

Mitoma, Auld, and Udenfriend (1957) showed that two protein fractions are involved in this reaction, a labile fraction I found in liver and a more stable fraction II found in kidney and heart. The system required N.A.D. or N.A.D.P. and iron together with an unknown but necessary coenzyme which can be replaced by tetrahydrofolic acid. Fraction I is deficient in phenylketonuria.

The deficiency of phenylalanine hydroxylase causes an excessive accumulation of phenylalanine in the blood and cerebrospinal fluid. The excessive phenylalanine is converted by its transaminase to phenylpyruvic acid, and this in turn is converted to phenyllactic acid, phenylacetic acid, and phenylacetyl glutamine, which are excreted in the urine. o-Hydroxyphenylacetic acid, m-hydroxyphenylacetic acid, and indole products derived from tyrosine and tryptophan are also found in the urine of such patients. The excessive phenylalanine inhibits the normal pathways of tyrosine metabolism, there is a decreased formation of melanine accounting for the blond hair and blue eyes; plasma adrenaline 
levels are low in phenylketonurics. The excessive phenylalanine or one of its products possibly damages the central nervous system; the patients are mentally retarded and have epileptic seizures and abnormal electroencephalograms.

The condition can be diagnosed by the presence of phenylpyruvic acid in the urine and an increase of phenylalanine in the plasma. Heterozygotes can be detected by phenylalanine tolerance tests. The homozygous condition can be ameliorated by giving the infants a diet low in phenylalanine, which has no effect on older children, demonstrating that early diagnosis of the disease is essential.

TYROSINOSIS This is a very rare inborn error of metabolism described by Medes (1932). Her patient was a male Russian Jew who excreted large quantities of $p$-hydroxyphenylpyruvic acid and other tyrosine metabolites but had no clinical symptoms. Medes, Berglund, and Lohmann (1927) found an excess of $p$-hydroxyphenylpyruvic acid in the urine of a patient with myasthenia gravis, and Felix, Leonhardi, and Glasenapp (1951) made similar observations on two patients with liver disease. The amount of $p$-hydroxyphenylpyruvic acid excreted was considerably less than $50 \mathrm{mg}$. per day and it is probable that these cases are of a different type of metabolic abnormality from the case described by Medes.

The metabolic defect is a deficiency of $p$-hydroxyphenylpyruvic oxidase which requires glutathione and either ascorbic acid or dichlorophenolendophenol as cofactors. In the patient with tyrosinosis only $p$-hydroxyphenylpyruvic acid is excreted but scorbutic guinea-pigs and scorbutic children (Huisman and Jonxis, 1957) excrete the p-hydroxyphenyllactic acid as well. The patient described by Medes could convert the pyruvic derivative to the lactic derivative; one would assume then that if the tissues contained large amounts of p-hydroxyphenylpyruvic acid the lactic acid would be formed, but the patient only excreted $p$-hydroxyphenylpyruvic acid. In various conditions in which $p$ hydroxyphenylpyruvic acid oxidase in the liver is impaired the lactic as well as the pyruvic derivatives are found in the urine. It may be that in the case of tyrosinosis the defect is analogous to phenylketonuria and the block is a defect of tyrosine transaminase. It is difficult to explain the absence of $p$-hydroxyphenyllactic acid in the urine with the presence of a system converting $p$-hydroxyphenylpyruvic acid to $p$-hydroxyphenyllactic acid in the patient.

ALKAPTONURIA This is a rare metabolic disease in which the enzyme homogentisic acid oxidase is lacking. Homogentisic acid, produced in the meta- bolism of phenylalanine and tyrosine, cannot be metabolized; it accumulates and is excreted in the urine. If the urine is allowed to stand it becomes dark and this sign leads to early recognition of the disease. Boedeker (1859) first diagnosed the disease with certainty and used the property of avid oxygen uptake to give the substance a name 'alkapton'. Garrod in 1909 wrote of the probable defect: 'We may further conceive that the splitting of the benzene ring in normal metabolism is the work of a special enzyme, that in congenital alkaptonuria this enzyme is wanting, whilst in disease its working may be partially or even completely inhibited'. The condition is compatible with long life. Except for the dark-coloured urine there are no clinical manifestations until the second or third decade when ochronosis begins to appear. Black pigments are deposited in various parts of the body, and eventually the patients develop deforming arthritis in middle age.

Garrod (1902) first described the inheritance of alkaptonuria and presented evidence that the condition was congenital and familial. He suggested that it was inherited as a single recessive gene. A study of the cases reported since that time has supported the view that the defect is due to a single recessive autosomal gene, and gains further support by the finding that a single enzyme system is inactive in this condition and that only one clinical form is known.

Since the feeding of homogentisic acid to alkaptonurics results in almost quantitative recovery from the urine, while no such accumulation occurs in normal individuals, it is postulated that the condition represents a metabolic block at the stage of homogentisic acid. An analysis of enzymes involved in tyrosine metabolism in normal and alkaptonuric liver showed that only homogentisic acid oxidase is missing in alkaptonuric liver ( $\mathrm{La} \mathrm{Du}$, Zannoni, Laster, and Seegmiller, 1958). Homogentisic acid is not converted into maleylacetoacetate but accumulates in the blood and is excreted in the urine. The homogentisic acid is at least in part responsible for the deposition of pigment in the tissues in this condition.

ALBINISM Albinism is an inherited defect of pigment cells, melanocytes, to form melanin. Patients with this condition have white or very pale yellow hair which is silky in texture. The pupils of the eye appear to be red and the iris is pink or bluish from reflected light. The intelligence of generalized albinos is normal but no large series have been studied. The condition is transmitted as a simple recessive, which is shown by the fact that 20 to $30 \%$ of the cases result from cousin marriages. 
The biochemical lesion of albinism consists of a failure of melanocytes to synthesize tyrosinase, a copper-containing oxidase required for the conversion of tyrosine to melanin (Fitzpatrick, 1960). Tyrosine is oxidized via 3,4 dihydroxyphenylalanine to 3,4 dopa quinone by tyrosinase in the presence of molecular oxygen. Ultimately dopa quinone forms melanin by a reaction which may or may not be enzymatic.

PARTIAL ALBINISM This is characterized by a congenital absence of pigment in specific areas of the body. Three varieties are known:- 1 Piebald albinism and 2 white forelock and spotting of the skin. These two forms are transmitted as simple dominants. 3 Albinism of the eye alone. This is a sex-linked recessive characteristic and is characterized by albinism of the fundus, hypoplasia of the macula, head nodding, nystagmus, and amblyopia. The pathogenesis of these conditions is not known.

ABNORMALITITES OF AMINO-ACIDS IN THE UREA CYCLE In the past few years inborn errors of metabolism involving the amino-acids of the urea cycle have been described. The current concepts on the formation of urea are shown in Figure 2.

Argininosuccinic aciduria Argininosuccinic acid was identified as the unknown ninhydrin-reacting material on paper chromatograms of the urine of two mentally retarded children (Westall, 1960). A case has also been reported by Levin, Mackay, and Oberholzer (1961). The patients had normal blood urea levels, suggesting that there is either another path of urea formation in these patients (Levin, Mackay, and Oberholzer, 1961) or that the defect is localized to one tissue, for example, the brain. In support of this concept Allan, Cusworth, Dent, and Wilson (1958) found higher concentrations of argininosuccinic acid in cerebrospinal fluid than in plasma. Sporn, Dingman, Defalco, and Davies (1959) have shown that rat brain incorporates labelled arginine into urea in vivo and can thus synthesize urea. Cusworth and Dent (1960) showed that arginino-succinic acid, like ethanolamine phosphate and $\beta$-aminoisobutyric acid, is excreted in human urine without tubular reabsorption.

Citrullinuria McMurray, Mohyuddin, Rossiter, Rathbun, Valentine, Koegler, and Zarfas (1962) have described the finding, during a routine amino-acid screening programme, of citrulline in the urine of a mentally retarded child aged 18 months. The concentration of citrulline in the plasma and the cerebrospinal fluid was increased when compared with a control group and suggests that the defect is unlikely to be of the renal tubules. A renal tubular defect may be the cause of increased citrulline in the urine of patients with Hartnup disease and with the Fanconi syndrome. Citrullinuria has previously been described in cystinuria in humans and canines (e.g., Dent and Rose, 1951). Asatoor, Lacey, London, and Milne (1962) consider that the citrullinuria in cystinurics is due to a small intestinal absorption defect for dibasic amino-acids and is formed from arginine. Visakorpi (1962) suggested that the excretion of citrulline by a mentally defective cystinuric was comparable to citrullinuria but this

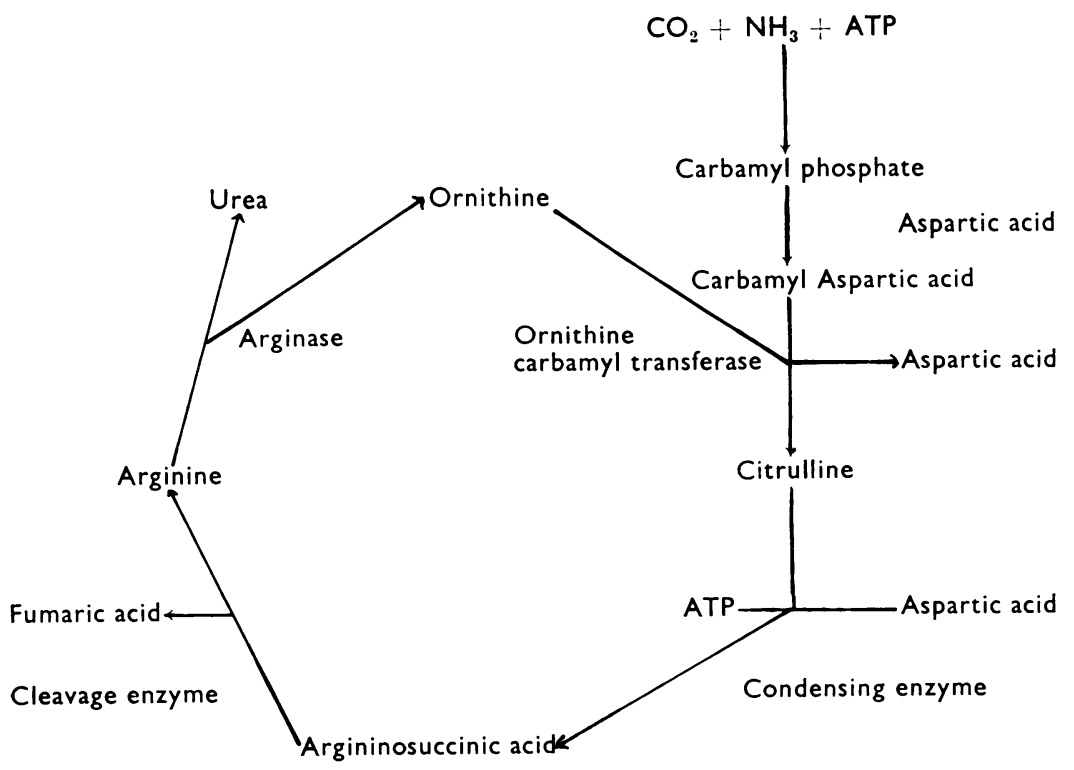

FIG. 2. The urea cycle. 
is unlikely. In the case described by McMurray and his colleagues (1962) the patient excreted urea in amounts comparable to those excreted by normal children, suggesting that the urea cycle is not seriously impaired in the liver. It may be that citrulline is produced in the brain as has been suggested for argininosuccinic acid.

Hyperammonaemia Russell, Levin, Oberholzer, and Sinclair (1962) have described two cousins who were mentally retarded and had cerebral degeneration. In both children the levels of ammonia in the blood and cerebrospinal fluid were elevated. There was no evidence of liver disease or excessive absorption from the gut. Examination of the liver after death showed a depression in the ornithine transcarbamylase activity. The blood urea was within normal limits; this suggests that there may be another method of urea production in these children.

MAPLE SUGAR URINE DISEASE In 1954 Menkes, Hurst, and Craig described a family in which four out of six infants, one girl and three boys, died during the first weeks of life with what appeared to be a congenital metabolic disease. The predominant signs were vomiting, muscular hypertonicity, and a maple syrup odour to the urine. Paper chromatography of the urine failed to reveal any abnormality in the amino-acid pattern.

In 1957 Westall, Dancis, and Miller described a 20-month-old infant who was mentally retarded, had muscular hypertonicity, and a maple syrup odour to the urine. An excess of leucine was found in the urine. Further investigations suggested a metabolic block in the degredative path of branched chain amino-acids. Further cases have been reported by Mackenzie and Woolf (1959) and by Lane (1961).

Lane suggested, on the basis of two possible cases related to the patient, that the condition was inherited as a simple recessive characteristic.

The urine in this disease contains large amounts of leucine, isoleucine, and valine; it also contains increased amounts of the $\alpha$-keto derivatives of these amino-acids (Dancis, Levitz, Miller, and Westall, 1959). Evidence indicates a block at a point beyond transamination $(\mathrm{A})$ at, or beyond, oxidative decarboxylation (B).

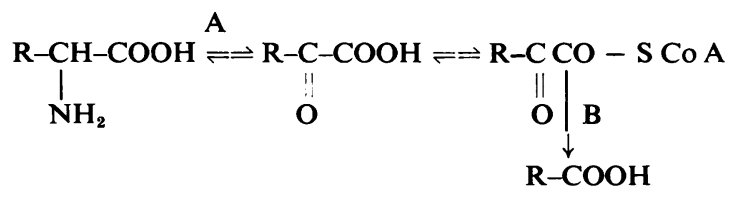

Transaminase was present in liver, brain, heart, and kidney at necropsy in the case described by Dancis, Levitz, and Westall (1960).
The urine also contains an amino-acid that was thought to be methionine. Dent and Westall (1961) found that the plasma methionine was increased when isoleucine was given to a patient with the abnormality. Norton, Roitman, Snyderman, and Holt (1962) consider that it is not methionine that is excreted but probably alloisoleucine. The maple syrup smell probably emanates from $\alpha$-oxoisocaproic acid, a keto-acid derived from leucine.

hyPERGLyCINAEMIA Childs, Nyhan, Borden, Bard, and Cooke (1961) described a child, 3 years old, who was investigated originally because of a failure to thrive, with acute exacerbations characterized by vomiting, lethargy, and irritability. The main findings were of developmental retardation, ketosis, neutropenia, hypogammaglobulinaemia, and periodic thrombocytopenia. The plasma levels of glycine, serine, alanine, isoleucine, and valine were raised but only glycine was present in excess in the urine. The toxic symptoms could be abolished by keeping the protein in the diet to less than $0.5 \mathrm{~g}$. per kilogram of body weight. Giving sodium benzoate lowered the level of glycine in the plasma causing a remission of the neutrophil leucopenia but it did not prevent the toxic symptoms. Leucine administration in the patient increased the plasma threonine but not in controls. It is not known whether the condition is genetically determined. The specific enzyme defect has not been localized. Kaser, Cottier, and Antener (1962) described a case of gluco-glycinuria in which the serum glycine level was normal, and it was thought that the glycinuria was due to a tubular defect and was therefore different from the case reported above.

histidinaemia Ghadimi, Partington, and Hunter (1961) reported a case of a 3-year-old child who was physically small with retarded speech and had excessive amounts of histidine in his urine and plasma. The patient's sister also had a raised plasma histidine level. Auerbach, DiGeorge, Baldridge, Tourtellotte, and Brigham (1962) have reported another case of histidinaemia and histidinuria in a 2-year-old child. This child had been well until it had a febrile fit. Davies and Robinson (1963) recently reported a further case of histidinaemia. These children excrete histidine, imidazole pyruvic, imidazole lactic, and imidazole acetic acid. They do not excrete urocanic acid, imidazole propionic, or formiminoglutamic acid. Histidine administration causes an increase in the plasma histidine but urocanic acid administration is accompanied by urinary excretion of urocanic acid, imidazole propionic acid, and formiminoglutamic acid. The enzyme deficiency seems to be of histidase (histidine- $\alpha$-deaminase) but 
urocanase action appears to be normal. The defect is probably inherited as an autosomal recessive character.

HYPERPROLINAEMIA Schafer, Scriver, and Efron (1962) have described hyperprolinaemia in a family, associated with nephropathy and deafness. The patient was a child admitted with fever, vomiting, and diarrhoea; he was deaf and had frequent clonic and tonic seizures, and the right kidney was hypoplastic and the left kidney deformed. The plasma contained an excess of proline and the urine an excess of proline and hydroxyproline. The child's father was normal but the mother was deaf and had a poorly functioning left kidney but a normal aminoacid chromatogram. Three sisters of the patient had abnormal electroencephalograms and hyperprolinaemia; two of these three had haematuria and two other sibs were normal. It is probable that glycine and hydroxyproline share a common tubular transport mechanism with proline, accounting for the occurrence of these two amino-acids with proline in some of the afflicted individuals. No $\triangle^{-1}$ pyrroline5-carboxylic acid could be detected in the urine. The defect may be a lack of the enzyme proline oxidase. Hydroxyproline is formed from proline and this is incorporated in collagen; these subjects may also have collagen defects.

$\beta$-AMINOISOBUTYRIC ACIDURIA $\beta$-Aminoisobutyric acid was identified in some samples of human urine by Crumpler, Dent, Harris, and Westall (1951). Study of population groups has suggested that the high excretor gene originates in Asia. The abnormality is familial with a recessive mode of inheritance. There is a marked difference in the excretion of $\beta$-aminoisobutyric acid in high and low excretors after intravenous administration of a test load, suggesting that the difference between high and low excretors lies in its metabolism; it may be that the acid is derived from thymine. An alternative method of formation from valine by way of a transamination reaction of methyl malonyl-semialdelyde with glutamate has been suggested by Kupiecki and Coon (1957).

$\beta$-Aminoisobutyric acid is excreted by patients with chronic myeloid leukaemia, liver disease, the nephrotic syndrome, and by very young infants.

cystathioninuria Harris, Penrose, and Thomas (1959) described cystathioninuria in a mentally defective patient in whose family two other members were found to secrete the substance. Increased amounts of cystathionine were found in the kidney and liver but it was not possible to tell if the amount in the brain was increased.
HYPOPHOSPHATASAEMIA In 1948 Rathbun described a 3-week-old infant with rachitic bone lesions and a diminution in the alkaline phosphatase activity in bone, intestinal mucosa, and kidney despite adequate doses of vitamin $D$; he suggested the condition be called hypophosphatasaemia. Fraser (1957) has reviewed the historical aspects. Sobel, Clark, Fox, and Robinow (1953) noted premature loss of teeth, observed that serum did not inhibit alkaline phosphatase activity, and presented data suggestive of hypersensitivity to vitamin D. Fraser, Vendt, and Christie (1955) and McCance, Morrison, and Dent (1955) discovered that the excretion of phosphoethanolamine in urine is an integral feature of the disease. Patients with the disease have knock knees, bowing of the femurs and tibias, enlarged wrists, and a protuberant abdomen. There is poor mineralization of bones and teeth, and at necropsy there is evidence of deficient calcification. Alkaline phosphatase is diminished or absent in serum, bone, and other tissues.

Hypophosphatasia is transmitted as an autosomal recessive. The heterozygous carriers can be sometimes detected by a decreased level of alkaline phosphatase in the serum and sometimes by an increased excretion of phosphoethanolamine in the urine.

It has been suggested that phosphoethanolamine is the true substrate of alkaline phosphatase and that a block in the hydrolysis of the ester occurs in this disease and this leads to a defect in calcification (Dent, 1956). As yet, there is no evidence in favour or against such a hypothesis.

PRIMARY HYPEROXALURIA AND OXALOSIS Primary hyperoxaluria is a rare disorder characterized by progressive bilateral calcium oxalate urolithiasis and nephrocalcinosis beginning in early childhood. The first reported case is probably that of Lepoutre (1925) who described bilateral urolithiasis in a $4 \frac{1}{2}$-year-old child with extensive crystalline deposits of calcium oxalate. In 1954 Aponte and Fetter described three cases of oxalate nephrocalcinosis in one family which were probably the first definite $N$ examples of oxalosis. The age of onset is usually about 1 to 4 years old, and the disease is characterized by repeated attacks of renal colic, haematuria, and the passage of calculi. Excessive amounts of oxalate are excreted in the urine.

Glycine is a significant precursor of oxalate (Crawhall, Scowen, and Watts, 1959) and in cases? of primary oxaluria the oxalate was not appreciably further oxidized to carbon dioxide but was excreted almost quantitatively in the urine. These authors found a considerably increased incorporation of $\stackrel{\mathbb{Q}}{\mathscr{Q}}$ labelled glycine into oxalate in hyperoxalurics; the same proportion of urinary oxalate was derived from 8 
glycine. Overproduction of oxalate from glycine and other precursors was therefore best explained by a block of glyoxalate degradation rather than by excess formation of glyoxalate. The enzyme defect may be a lack of glyoxylic glutamic transaminase or of glyoxylic dehydrogenase. Administration of sodium benzoate leads to an increased excretion of glycine as hippurate and causes some improvement.

The disease is possibly due to a rare recessive character (Archer, Dormer, Scowen, and Watts, 1958). The detection of heterozygotes is at present impossible. It may be that people who have recurrent oxalate stones represent carriers of this recessive character, but the available evidence does not yet support this view.

\section{DISTURBANCES OF CARBOHYDRATE METABOLISM}

PENTOSURIA The presence of pentose in urine was first described by Salkowski and Jastrowitz (1892). Much of our present knowledge of the clinical aspects of the disease, its genetic transmission, and the nature of the urinary sugar are due to the careful observations of Enklewitz and Lasker (e.g., Lasker, Enklewitz, and Lasker, 1936). The condition appears to be harmless to health and wellbeing. It is found

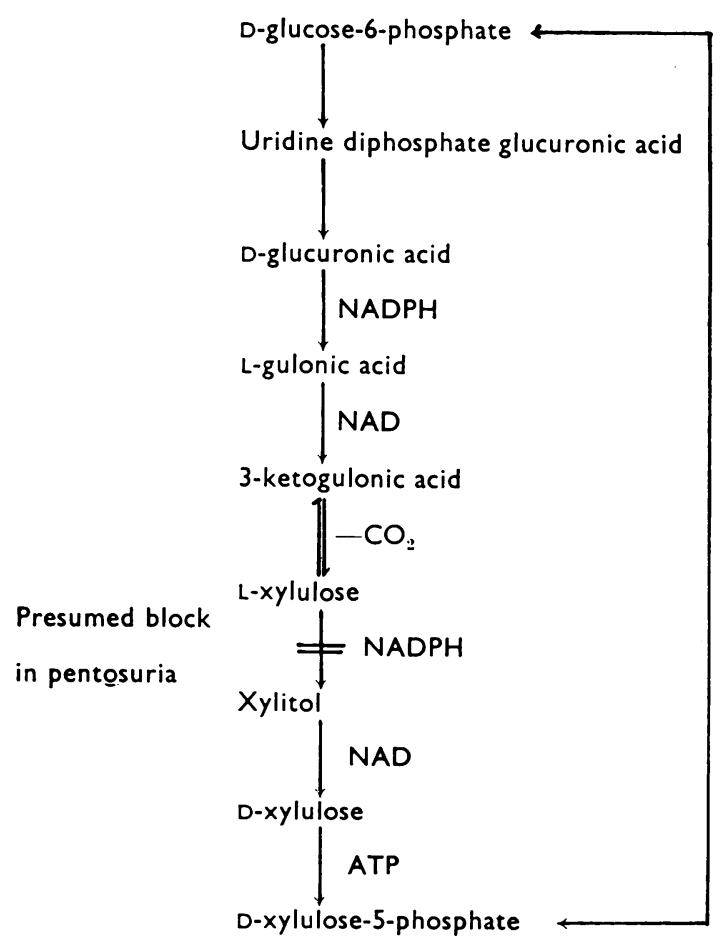

FIG. 3. The defect in pentosuria. almost exclusively in Jews and causes no decrease in life expectancy. It is probable that the condition is transmitted by a recessive gene. The pentose sugar that is excreted in pentosurics is L-xylose. L-Arabitol is also excreted in the urine; this sugar may be derived from L-xylulose by reduction.

In 1936 Enklewitz and Lasker showed that there is a direct relationship between the amount of glucuronic acid administered and the amount of L-xylulose excreted. Since feeding glucuronic acid to normal individuals does not produce this effect, they postulated a defect in the system that decarboxylates glucuronic acid to xylulose. Glucuronic acid is thought to be metabolized to D-xylulose by the pathway shown in Figure 3. The work of Touster (1960) suggests that the block in pentosuria is at the level of the N.A.D.P. linked L-xylitol-dehydrogenase. Hiatt (1958) demonstrated that labelled glucuronolactone was converted to L-xylulose but not to ribose, supporting this view, and Bozian and Touster (1959) that administration of glucuronolactone to pentosuric individuals caused an increase in plasma xylulose levels in contrast to the levels in normal subjects. Freedberg, Feingold, and Hiatt (1959) used a specific enzymatic method to measure L-xylulose levels in serum and urine and by means of a glucuronolactone load test they were able to detect heterozygotes.

FRUCTOSURIA Essential fructosuria is a rare error of metabolism characterized by a congenital inability to utilize fructose completely. In this type of abnormality the individuals show no clinical symptoms and the condition is harmless. The condition is transmitted as an autosomal recessive gene; the heterozygote condition cannot yet be detected.

In the normal individual when fructose is ingested there is a rapid rise of the respiratory quotient and elevation of the blood lactic acid. Patients with fructosuria do not show this response. At the present time the evidence is in favour of a defect of hepatic fructokinase. It is possible that the defect is in the utilization of fructose-1-phosphate. The enzyme for the conversion of fructose-1-phosphate to fructose6-phosphate is not present in liver and it may be that the fructose-1-phosphate accumulates and is excreted.

FRUCTOSE INTOLERANCE A congenital disease with severe clinical manifestations was described by Chambers and Pratt (1956). Administration of fructose leads to an excessive and prolonged rise in fructose in the blood, the blood glucose falls and this is accompanied by nausea, haemorrhagic vomiting, trembling, profuse sweating, and somnolence. After cessation of the symptoms there is a slight icterus, albuminuria, and aminoaciduria. The inheritance of 


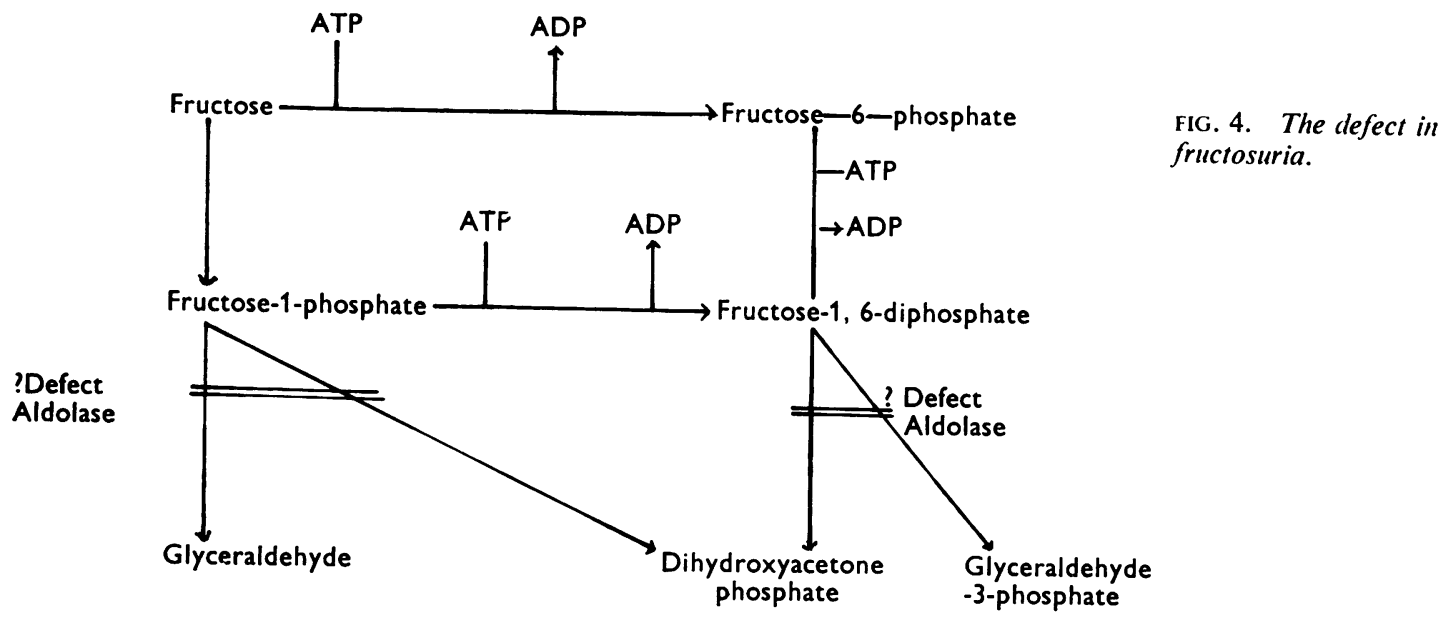

the disease seems to be of an autosomal recessive type.

Froesch, Prader, Wolf, and Labhart (1959) noted a rapid and marked decrease in serum inorganic phosphate accompanying the decrease in the blood glucose after intravenous fructose administration. The drop was attributable to binding of phosphate with fructose to produce fructose-1-phosphate. The decreased utilization of fructose-1-phosphate would account for the slow release of inorganic phosphorus. They postulated a deficiency of fructose-1-phosphate aldolase, but this was not demonstrated by liver biopsy, and that accumulation of fructose-1phosphate inhibited utilization of fructose. The authors suggest that it is unlikely that the cases are homozygotes and those with benign fructosuria are heterozygotes for the same defective gene. Dubois, Loeb, Ooms, Gillet, Bartman, and Champenois (1961) demonstrated a defect in the liver aldolase in these patients. Nikkila, Somersalo, Pitkanen, and Perheentupa (1962) showed that the fructose-1phosphatase aldolase was absent in the liver and the fructose-1, 6-diphosphate aldolase was $10 \%$ of that found in normal subjects. They suggested that fructose releases homeostatic mechanisms and hypoglycaemia is a result of excessive insulin secretion, but Froesch, Prader, Wolf, and Labhart (1959) suggested that the hypoglycaemia is due to inhibition of phosphoglucomutase by fructose-1phosphate rather than by release of insulin.

galactosaemia This is a hereditary condition characterized by an inability to convert galactose to glucose in the normal manner. Infants with this condition appear normal at birth but after a few days of milk feeding they begin to vomit, become lethargic, and fail to gain weight. Prolonged jaundice may occur in the neonatal period and the liver shows fatty infiltration which readily proceeds 음 to cirrhosis if milk feeding persists. Ascites and oedema may develop and the child may die in the $\subseteq$ neonatal period. Those who survive are malnourished and dwarfed; at 2 to 3 months of age they $\vec{\varphi}$ are mentally retarded and have cataracts. These $\omega$ patients have a reducing substance, galactose, in their urine together with aminoaciduria and albuminuria. The aminoaciduria is primarily renal in origin, and the amino-acids are mainly of the simple aliphatic chain type, e.g., serine, alanine, and glycine. The patients have high blood galactose levels, and ingestion of galactose often depresses the blood glucose, possibly by the release of insulin.

The abnormality is transmitted as an autosomal recessive. Carriers of the abnormal gene may be found on the basis of abnormal galactose tolerance tests and also by the presence of reduced amounts of galactose-1-phosphate uridyl transferase in erythrocytes.

The condition is due to a lack of galactose-1-

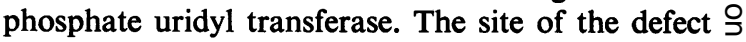
is based on the results of two types of experiment. $\rightarrow$ Schwarz, Golberg, Komrower, and Holzel (1956) ․․ showed that when milk was given to a galactosaemic No child there was an abnormal accumulation of galactose-1-phosphate in the red cells; this meta- O bolite was not found in normal children. This $\omega$ suggested that the block was beyond galactose-1phosphate and that galactokinase was present in 6 adequate amounts. Isselbacher, Anderson, Kurahashi, and Kalckar (1956) demonstrated that $\stackrel{+}{-}$ uridine diphosphate galactose-4-epimerase and uridyl diphosphate glucose pyrophosphorylase, the enzymes needed for the third and fourth steps, were present in normal amounts. Galactose-1-phosphate uridyl transferase could not be demonstrated in the erythrocytes of galactosaemic children. Anderson, 


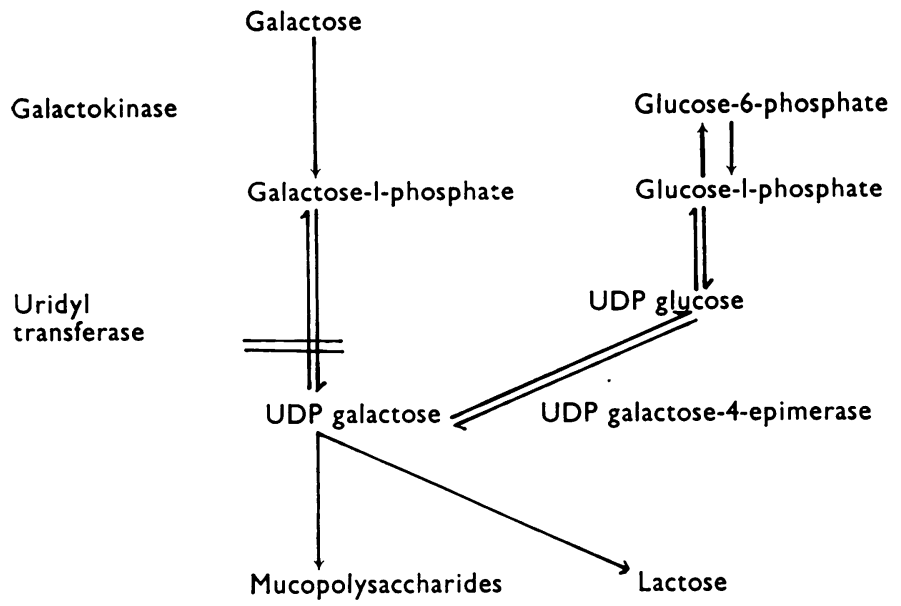

FIG. 5. The defect in galactosaemia.

Kalckar, and Isselbacher (1957) demonstrated a lack of the enzyme in the liver of two afflicted patients. It has been suggested that there is an alternative path of galactose metabolism bypassing the transferase system, for example, U.D.P.-galactose pyrophosphorylase, allowing galactose-1-phosphate utilization and incorporation into U.D.P. galactose. The U.D.P.-galactose pyrophosphorylase is deficient at birth and matures with age, possibly accounting for these patients' increased tolerance for galactose with age. Support for the idea of an alternative pathway has come from the work of Elder, Segal, Maxwell, and Topper (1960), who demonstrated that the ability of galactosaemics to oxidize a tracer dose of ${ }^{14} \mathrm{C}$ galactose to ${ }^{14} \mathrm{CO}_{2}$ was greatly increased by menthol or progesterone. Maxwell and Topper (1961) observed that steroids exert a stimulating effect on galactose oxidation in liver slices.

GLYCOGEN STORAGE DISEASE This is an overall term applied to a group of congenital and familial diseases characterized by the deposition of abnormally large quantities of glycogen in the tissues. Cori (1957) has recommended a classification based upon specific causative enzyme defects.

Type 1 Glucose-6-phosphatase deficiency hepatorenal glycogenosis von Gierke (1929) reported a condition characterized by excessive enlargement of the liver and other organs during early infancy due to accumulation of glycogen. The condition is characterized by convulsions due to hypoglycaemia, failure to thrive, severe acidosis, and eruptive xanthoma. Growth and development is retarded and death frequently occurs in the first two years of life.

The condition is transmitted as a simple autosomal recessive. The heterozygous carrier can be detected by raised glucose-6-phosphate and fructose-6phosphate levels in the red cells. Cori and Cori
(1952) first reported the abnormal biochemical findings in this type of glycogen storage disease. The glycogen in the liver is above $4 \%$ wet weight and has a normal structure; phosphorylase, amylo-1, 6glucosidase, phosphoglucomutase, U.D.P.G.-glycogentransglucosylase, and amylo $(1,4 \rightarrow 1,6)$ transglucosidase are normal or only slightly reduced. The glucose-6-phosphatase is absent or very much reduced. Hers (1959) considers that only the complete absence of glucose-6-phosphatase can be held responsible for the disease. Schwartz, Ashmore, and Renold (1957) found that although affected infants show a normal response to intravenous glucose, galactose is excreted as lactic acid and not converted to glucose as in the normal infant. This indicates an inability to convert glucose-6-phosphate to glucose. The absence of glucose-6-phosphatase deprives the patient of readily accessible glucose, thus causing hypoglycaemia, which in turn causes ketosis, convulsions, increased gluconeogenesis from proteins, starvation diabetes, and poor response to glucose tolerance tests. Giving adrenaline and glucagon to a well-nourished child with a wellglycogenated liver results in a 40 to $60 \%$ rise in blood glucose within 10 to 20 minutes by virtue of the depolymerization of stored glycogen, and its eventual conversion to glucose by means of the stimulating effect of adrenaline and glucagon on phosphorylase. There is increasing evidence that the absence of glucose-6-phosphatase may not account for all the clinical features of the disease.

The effect of glucagon on these children has been studied intensively. Carson and Koch (1955) showed that in classical glycogen storage disease only slightly diminished or normal results to glucagon administration were found. This has been explained by the effect of the debrancher enzyme, amylo-1,6glucosidase, releasing free glucose from glycogen 


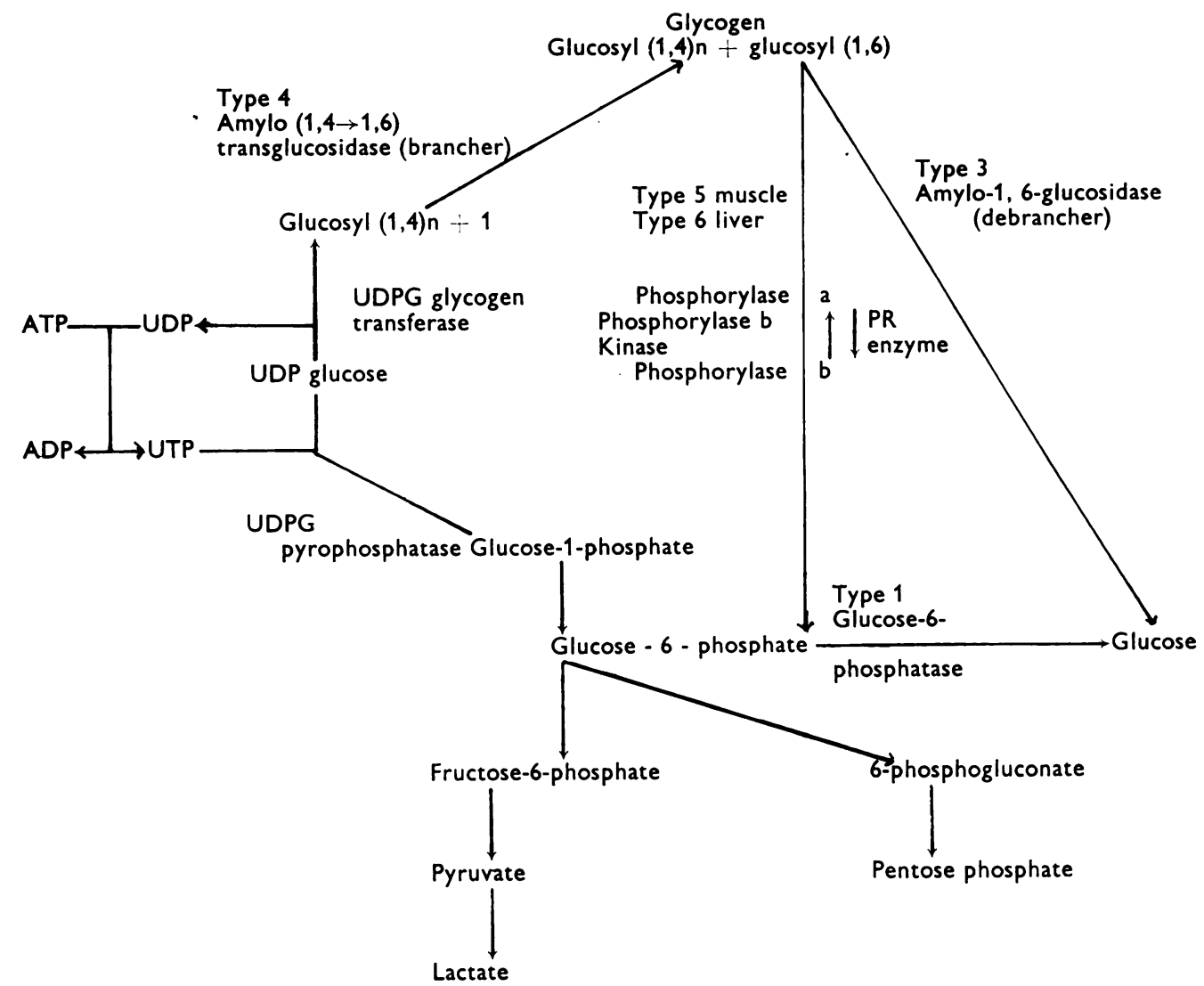

Type 1 Glucose-6-phosphatase deficiency hepato-renal glycogenosis

Type 3 Debrancher deficiency limit dextrinosis

Type 4 Brancher deficiency amylopectinosis

Type 5 Myophosphorylase deficiency glycogenosis

Type 6 Hepatic phosphorlyase deficiency glycogenosis

FIG. 6. The glycogen storage diseases.

without the need of a specific phosphatase. Lowe, Sokal, Mosovich, Sarcione, and Doray (1962) found that there was no correlation between glucose-6phosphatase and fasting hypoglycaemia in a series of nine children with the abnormality. They found major discrepancies between enzyme determinations in vitro and the clinical condition. The disorder has recently been treated by giving glucagon after feeding (Lowe et al., 1962). Eberlein, Illingworth, and Sidbury (1962) have treated glucose-6phosphatase deficiency with $9 \alpha$-fluor-11 $\beta$-hydroxy$17 \alpha$-methyl testosterone (Halotestin) and brought about clinical and biochemical improvement; the adrenaline response returned to normal under treatment. These findings suggest that the disease is likely to prove more complicated than a simple deficiency of glucose-6-phosphatase.

Type 2 Glycogen storage disease of the heart This disease has been extensively reviewed by di
Sant' Agnese, Andersen, and Mason (1950). The condition becomes manifest in early infancy; the infant feeds poorly, becomes listless, and fails to $ᄋ$ gain weight. This is followed by episodes of inter- $D$ mittent cyanosis, especially during feeding, leading to attacks of dyspnoea with no specific cause. The infants usually die of cardiac failure or broncho- of pneumonia. The heart is enlarged and appears $N$ globular on $x$-ray examination. At necropsy it weighs $\mathfrak{\omega}_{\omega}$ two to five times the normal for the age. Histo- 0 logically there is massive infiltration with glycogen. Sometimes excessive amounts of glycogen are $\mathbb{\Phi}$ deposited in smooth and striated muscles and $\stackrel{\oplus}{?}$ sometimes excessive infiltration with a basophilic 0 substance is found in skeletal muscle. The condition $\stackrel{0}{\circ}$ is probably transmitted as a single recessive auto- $\mathbb{\mathbb { D }}$ somal gene. No enzymic defect has been advanced $\stackrel{\oplus}{\circ}$ to account for this disease. Hers (1961) recently described a defect in the hydrolysis of maltose to 
glucose ( $\alpha$-glucosidase) in liver and heart. This finding would suggest a role for the hydrolytic path of glycogen breakdown through the oligosaccharides. An alternative explanation involving a transglycosylation reaction immediately before the debranching enzyme has been suggested. At present we do not know the site of the enzyme defect with certainty.

Type 3 Debrancher deficiency limit dextrinosis The clinical descriptions of this disease are similar to those found in glucose-6-phosphatase deficiency but they tend to be milder and difficulties with hypoglycaemia and development are less severe. It is possible that early cases reported as von Gierke's disease were actually deficiency of the debranching enzyme.

In the original case described by Forbes (1953) abdominal enlargement was found at the age of 1 year, fasting blood sugars were slightly below normal, and there was a diminished response to adrenaline. The fasting blood sugars were in the normal range by the age of 12 , when the abdominal distension decreased. At this age the liver function tests became abnormal. Liver biopsy showed that parenchymal cells were packed with glycogen, and a definite increase in the periportal connective issue.

Illingworth, Cori, and Cori (1956) showed that the content of muscle and liver glycogen was increased and that the glycogen had an increased number of branch points and short external chains. There was an absence of detectable amylo-1,6 glucosidase activity with normal amounts of phosphorylase and glucose-6-phosphatase. Hers (1961) used a new method for measuring the enzyme based on the observation that the enzyme catalysed a limited reincorporation of ${ }^{14} \mathrm{C}$-labelled glucose into the phosphorylase limit dextrin. As a result it was shown that the disease was present with enzyme defects in liver and muscle in one variant or with a defect in liver but not in muscle in another variant.

Information regarding the genetics of the condition is meagre. It is probable that inheritance is through a single recessive autosomal gene.

Type 4 Brancher deficiency amylopectinosis In 1956 Andersen reported on a 17-month-old white male infant whose liver showed glycogen which on analysis was less branched and had larger inner and outer branches than normal. The complaints were primarly hepatic, with oedema, ascites, and bleeding tendencies. Liver function tests were abnormal but the blood sugar was normal and no acidosis was present. A glucose tolerance test showed a moderate rise and a slow fall of the blood glucose level. The response to adrenaline was moderate, but less than in normal individuals. Necropsy showed glycogen infiltration of liver, spleen, lymph nodes, and intestinal mucosa together with nodular cirrhosis of the liver. No glycogen was found in the kidneys. The glycogen has different characteristics to that found in von Gierke's disease in that it was sticky, hard to handle, and slow to precipitate.

Illingworth and Cori (1952) studied the abnormal glycogen and found a decreased number of branch points and a greater chain length than normal. It seems that there are fewer branch points and significantly longer chains. Cori (1957) postulated that these defects could be explained by a deficiency of the brancher enzyme amylo $(1,4 \longrightarrow 1,6)$ transglucosidase, but unfortunately not enough tissue was available for direct enzymatic measurement.

Sidbury, Mason, Burns, and Ruebner (1962) have described a second case of abnormal glycogen structure. The liver, kidney, muscle, and blood contained an unusual polysaccharide with an increased average outer chain length.

The hereditary transmission of the condition is not known, for although the sibling of the case described by Andersen died of 'glycogen storage disease' it is not known which type of the disease it was.

Type 5 Myophosphorylase deficiency glycogenosis At least eight patients with this abnormality have been described. McArdle (1951) described a 30year-old man who had pain, weakness, and stiffness of muscles after exercise; the symptoms disappeared at rest. On examination it was found that 10 to $20 \%$ of the normal work could be performed by the forearm and hand muscles in the ischaemic state but maintenance of the contracted state gave localized swelling. There was a fall in the lactate and pyruvate levels in the venous return in blood coming from an ischaemic muscle, in contrast to the sharp increase in these metabolites in the blood from normal muscle. There was a normal hyperglycaemic response to adrenaline but a smaller rise in blood lactate than produced in a normal person. The best confirmation of the abnormality is the inability to detect an increased blood lactate level after exercise, especially under ischaemic conditions. Histologically excessive amounts of diffuse granular glycogen are found in muscle. Homogenates of biopsy material cannot form lactate but have an intact glycolytic capacity, as shown by normal lactate production after the addition of glucose-1-phosphate. There is no detectable phosphorylase $a$ and $b$ activity. The PR enzyme catalysing the conversion of phosphorylase $a$ to $b$ and phosphorylase kinase are normal. It is not known why there is not a greater accumulation of glycogen in phosphorylase-deficient muscles. It may be due to breakdown by hydrolytic enzymes or to a decreased extraction of blood glucose by muscle. It is also not known whether there is a 
deficiency of phosphorylase in cardiac muscle. Such a deficiency may not be detectable since cardiac muscle can use substrates other than glucose for energy. Hepatic phosphorylase activity is intact in this disease.

Immunological studies have shown that muscle phosphorylase is either completely lacking or so modified that it does not react immunologically. There is insufficient evidence to determine the mode of inheritance but the absence of a single enzyme in an otherwise complete chain suggests that the defect is a result of a single genetic determination. The fall in lactate would seem to result from its being used at the same time as its production is curtailed. Schmid and Hammaker (1961) have described a family study and, using the failure of the level of the blood lactate to rise after exercise, suggest a recessive mode of inheritance.

di Sant 'Agnese, Andersen, and Metcalf (1962) described a child with excessive muscle glycogen. They pointed out that McArdle's syndrome usually appears in the second decade and this was the first recorded instance of it being observed in a child.

Type 6 Hepatic phosphorylase deficiency glycogenosis Hers (1959) first described glycogen storage disease associated with a diminished hepatic phosphorylase activity. In one family three children were affected: one had decreased phosphorylase with a normal level of glycogen; the other two had phosphorylase activities that were not decreased but had increased liver glycogen. In the first case it may be that glycogen breakdown via a non-phosphorolytic pathway might be sufficient to limit the accumulation of glycogen, and in the second two cases it may be that the system is not behaving in vivo as in vitro. Myophosphorylase is apparently normal.

U.D.P.G. glycogen transferase deficiency Lewis, Stewart, and Spencer-Peet (1962) described a case of infantile hypoglycaemia in which there was a deficiency of U.D.P.G.-glycogen 1,4-transglucosylase (U.D.P.G. glycogen transferase). A pair of identical twins was investigated to determine the cause of profound hypoglycaemia. Glucose tolerance tests showed a reduced capacity to assimilate glucose and a rise in blood glucose following the administration of glucagon suggested an impaired ability to store glycogen. A liver biopsy showed that while normal amounts of phosphorylase, U.D.P.G. pyrophosphorylase, and glucose-6-phosphatase were present, there was a complete absence of U.D.P.G.-glycogen 1,4-transglucosylase. The father and three siblings have abnormalities of carbohydrate metabolism, suggesting that the condition is an inborn error of metabolism.

The glycogen storage diseases illustrate some of the problems in the investigation of inborn errors of metabolism. It is an oversimplification of the problem to suggest that every single-enzyme defect demonstrated in vitro is necessarily the cause of the illness. Isolated enzyme reactions do not occur in living tissue but are part of an integrated whole. For some years, however, each enzyme defect was equated with a more or less well-defined clinical type. Eberlein, Illingworth, and Sidbury (1962) describe a family in which a male child had a deficiency of glucose-6-phosphatase although the muscle glycogen was normal. A younger sister was investigated two years later for a very similar clinical picture. Her glucose-6-phosphatase level was only 'moderately' decreased but she had a deficiency of the debranching enzyme, amylo-1,6-glucosidase. Both children had incompletely degraded glycogen, or 'limit dextrin' in the red cells. The father and a third sibling had twice the normal amount of glycogen in the red cells.

Other multiple defects already reported include the case of Sokal, Lowe, Sarcione, Mosovich, and Doray (1961) who noted a deficiency of both phosphorylase and glucose-6-phosphatase in one patient. Calderbank, Kent, Lorber, Manners, and Wright (1960) described a glucose-6-phosphatase defect in the sibling of a patient previously shown to have an amylo-1,6glucosidase defect. Before any generalizations are made it must be conclusively proved that these are genetic and not post-genetic defects.

INTESTINAL GLYCOSIDASE DEFECTS Holzel, Schwarz, and Sutcliffe (1959) have described two children in one family in whom there was defective lactose absorption causing malnutrition in infancy. The children had chronic diarrhoea. Oral lactose tolerance tests failed to increase the blood glucose and led to watery stools of low $p \mathrm{H}$ containing lactic and other acids. The good state of health of a 10year-old child with lactose deficiency is in keeping with endogenous formation of galactose. Diarrhoea, in which thin, foamy, bulky stools were produced, due to a lack of invertase, was described by Weijers, van de Kamer, Dicke, and Ijsseling (1960). There was an elevation of blood glucose after oral administration of maltose but no elevation of blood glucose after an oral sucrose tolerance test. This suggests that the two disaccharides are dealt with by different enzymes. The same authors have also reported diarrhoea due to a deficiency of maltose. Patients with invertase deficiency do not tolerate dextrin and show a decreased elevation of blood sugar following starch loads.

Holzel, Mereu, and Thomson (1962) have described a case of severe lactose intolerance associated with lactosuria. Six cases have now been recorded with this condition. It is probable that these children 
cannot metabolize lactose whereas in the cases with defective lactose absorption the defect is limited to the hydrolytic enzymes of the gut.

LACTATE METABOLISM DEFECT Hartmann, Wohltmann, Purkerson, and Wesley (1962) described a child that appeared to have an abnormal carbohydrate metabolism. The child had a persistent acidosis and secreted an acid urine. The lactic acid level in the blood was persistently elevated. The liver glycogen was decreased, the glucose-6phosphatase was increased in the liver, and the red cells had an increased rate of glycolysis. The biochemical explanation of these findings is still in doubt but it seems from the published case that there is a defect in the N.A.D.: N.A.D.H. system associated with pyruvate metabolism. The acetylation of other substances may be decreased, but the precise abnormality in pyruvate metabolism has not yet been demonstrated.

HEREDITARY SPHEROCYTOSIS This is a congenital haemolytic disorder characterized by the presence of spherocytes in the peripheral blood. The patients have a mild degree of anaemia, varying from patient to patient, but it is rarely severe. There is a slight increase in unconjugated bilirubin in the serum, an increased excretion of stercobilinogen in the stools, and a mild to moderate reticulocytosis. From time to time the patients developed a sudden crisis, characterized by malaise, anorexia, mild fever, and bouts of jaundice. There is sudden destruction of the circulating erythrocytes and a decrease of erythropoiesis with maturation arrest in the bone marrow. The cause of these crises is not well understood, but they are frequently associated with infections.

Laboratory studies show an increased osmotic fragility of red cells and an increased mechanical fragility. The cells in hereditary spherocytosis undergo lysis five or 10 times as rapidly as normal cells when incubated at body temperature for 48 hours. This abnormal degree of autohaemolysis can be largely prevented by the addition of glucose.

The overall rates of glucose consumption and phosphate exchange in hereditary spherocytes are normal but when the cells are incubated in plasma containing ${ }^{32} \mathrm{P}$ a disproportionately small amount of ${ }^{32} \mathrm{P}$ is recovered from the intracellular and stromal phosphate esters and a proportionately greater amount from the inorganic phosphate pool of the cell. It appears that the movement of phosphate into various intermediates deviates from normal but the exact nature of the abnormality is at present not clear; possibly there are abnormalities of enolase or a phosphokinase. It has been suggested that the maintenance of the biconcave shape of red cells depends on an adequate provision of energy and this is deficient in hereditary spherocytosis. Adenosine, which restores the phosphate changes in affected cells to normal, appears to replace the deficit. The red cells in the spleen may be deprived of glucose and are thus more readily removed from the circulation. Splenectomy does not alter the metabolism of the red cell.

Hereditary spherocytosis is transmitted as an autosomal dominant with most of the afflicted individuals being heterozygotes. It is not yet certain whether the dominance is complete.

HEREDITARY NON-SPHEROCYTIC HAEMOLYTIC ANAEMIA Patients with this disease usually present with jaundice and anaemia. There may be a history of weakness, malaise, and abdominal pain with hepatic or splenic enlargement. In children it may be confused with haemolytic disease of the newborn but the Coombs test is negative. Examination of the red cells shows no stippling, sickling, or fragmentation but there is a reticulocytosis, hyperbilirubinaemia, and other signs of excessive haemolysis.

The condition has been reported in about a dozen families and it appears to be transmitted as an autosomal dominant, with a variable degree of penetrance. It is quite possible that the disease is heterogenous because glucose affects autohaemolysis in some families but not in others. In some cases there is a normal rate of glycolysis and ${ }^{32} \mathrm{P}$ exchange but increased amounts of 2,3-diphosphoglycerate in the red cell. In others there is a low content of ATP, deficient glucose consumption, and a decreased ${ }^{32} \mathrm{P}$-orthophosphate exchange.

Newton and Bass (1958) found that some patients with non-spherocytic haemolytic anaemia had unstable reduced glutathione and diminished glucose6-phosphate dehydrogenase activity. The Heinz bodies formed after incubation with acetyl-phenylhydrazine were identical to those seen in drugsensitive subjects, but these patients differ from drug-sensitive individuals in that in them the red cell survival time is shortened.

HEREDITARY DRUG-INDUCED HAEMOLYTIC ANAEMIA Cordes (1926) reported haemolytic anaemia associated with pamaquin (an 8-aminoquinoline compound) therapy. The introduction of primaquine, a therapeutically more effective 8-aminoquinoline derivative in 1950, re-opened the study of this problem and in 1952, Hockwald, Arnold, Clayman, and Alving reported that primaquine induced intravascular haemolysis in $10 \%$ of Negroes but rarely in Caucasians. Two years later it was demonstrated that sensitivity to haemolytic anaemia induced by these drugs was a property of the red 


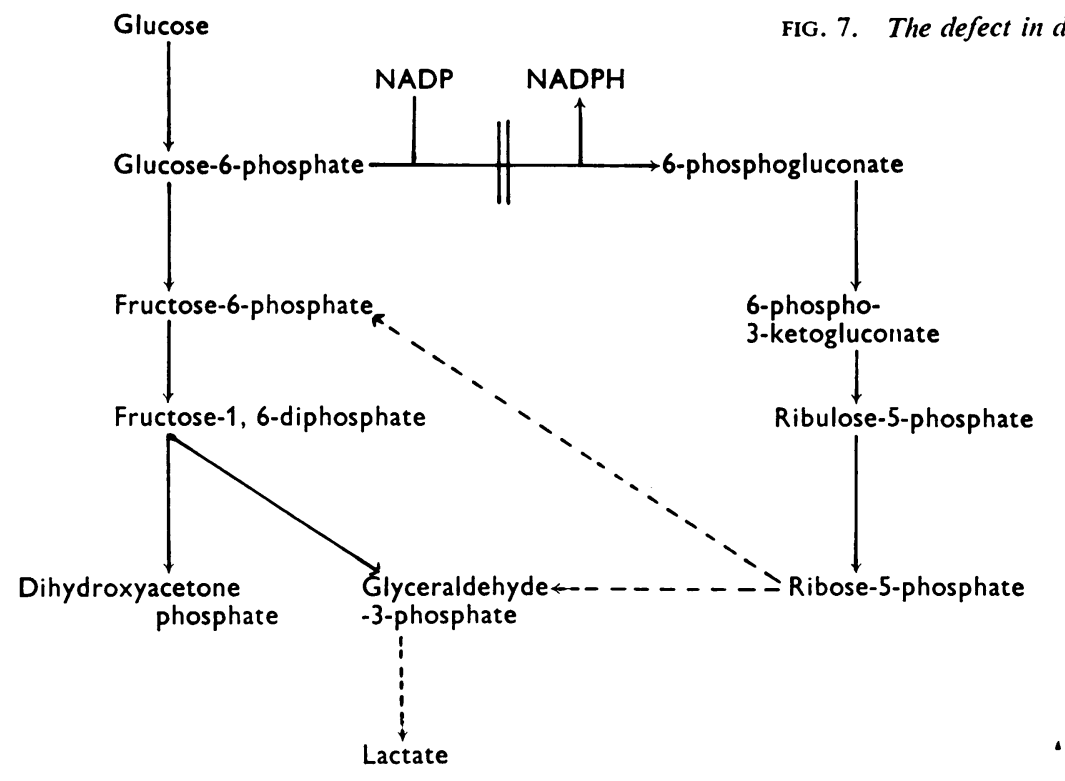

blood cell due to the presence of abnormal erythrocytes (Dern, Weinstein, Le Roy, Talmage, and Alving, 1954).

The haemolytic cycle consists of three phases. The first is an acute haemolytic phase, characterized by a fall in haemoglobin, a rise in the reticulocytes, and a darkening of the urine; it has been shown that about half the original red cell population is destroyed in this time. The second phase is of recovery, lasting three to four weeks, in which the haemoglobin concentration rises and the reticulocyte count falls. This passes to a phase of equilibrium which is followed by a maintenance of normal haemoglobin levels and a normal reticulocyte count.

The disease is also induced by naphthalene, nitrofurantoin, and fava beans. In fava bean sensitivity there is another defect, because in every case of favism the defect associated with primaquine sensitivity is present but patients with the latter defect can eat fava beans without haemolysis. The defect is transmitted as a sex-linked dominant trait. There is a marked degree of variability in the degree of penetrance, especially amongst females.

Carson, Flanagan, Ickes, and Alving (1956) showed that there is a deficiency of glucose-6phosphate dehydrogenase in the erythrocytes from primaquine-sensitive individuals. This can be shown by the fact that dilute haemolysates of drug-sensitive erythrocytes are unable to promote the reduction of oxidized glutathione when glucose-6-phosphate is the substrate. Oxidized glutathione is normally reduced when N.A.D.P. or 6-phosphogluconate is supplied. The enzyme deficiency is particularly severe in older red cells. There is evidence that a stromal factor inactivates the enzyme in drugsensitized cells but not in normal cells. The glucose6-phosphate dehydrogenase activity in leucocytes is normal in primaquine-sensitive Negroes but is decreased in Caucasian subjects. The red cells from sensitive subjects are deficient in reduced glutathione and in total glutathione. The content of N.A.D.P. is reduced and possibly that of N.A.D.; the glutathione reductase is increased. The catalase is decreased in the sensitive red cells but the aldolase is increased. The deficiency of glucose-6-phosphate dehydrogenase results in an abnormality of the oxidation of glucose in sensitive red cells via the hexose monophosphate shunt, resulting in a failure to reduce oxidised glutathione and this in turn is responsible for the low glutathione levels in sensitive individuals. The defect can be diagnosed by a deficiency of glucose-6-phosphate dehydrogenase in red cells and by the glutathione stability test.

\section{DISTURBANCES IN ENDOCRINE METABOLISM}

THYROID The biosynthesis of thyroid hormone takes place through a series of separate steps. Iodide is absorbed through the gastrointestinal tract as inorganic iodide and is rapidly distributed throughout the extracellular fluid of the body. Some of the iodide is excreted through the kidneys but most is trapped within the thyroid gland and is oxidized to elemental iodine. Iodide trapping is oxygen dependent and is inhibited by cyanide, azide, and sulphydryl inhibitors; it is enzymically controlled 
Extracellular

Intracellular

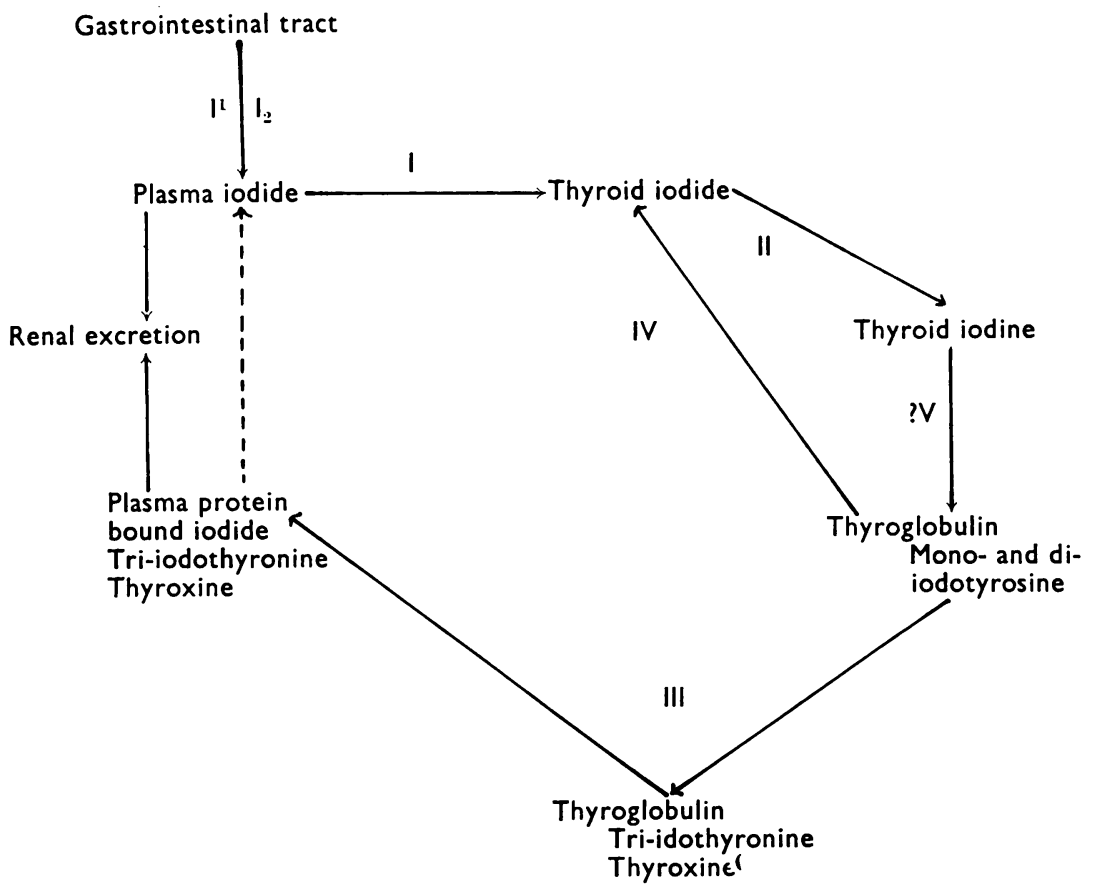

FIG. 8. Iodine metabolism.

and oxidative phosphorylation is involved. The normal resting thyroid maintains a $20: 1$ concentration ratio of iodide against the plasma. Thiocyanate and perchlorate ions prevent iodide trapping and release iodide; their site of action is not known. A congenital defect of iodide trapping and of a failure in the formation of organic iodide have been described.

The next step in thyroid hormone synthesis is the incorporation of iodine into the 3 position in tyrosyl residues to form mono- and di-iodotyrosines. The iodination may be linked with the oxidation of iodine and although it is thought that the oxidation requires peroxidase, the nature of the mechanism is not yet known.

The next step is the condensation of some of the iodinated tyrosyl residues to form iodinated thyronines, thyroxine, and tri-iodothyronine; coupling is thought to occur when the amino-acids are linked to peptides and is accelerated by oxygen. The reaction may depend on the formation of free iodine or on a more specific mechanism. Although no enzyme has been demonstrated for this step, coupling does not proceed in cell-free homogenates but it does in slices, suggesting that the formation is enzymically controlled or requires a high degree of cellular organization. A defect in this step results in cretinism from a failure of iodotyrosines to couple.

The remainder of the iodinated tyroxyl residues are dehalogenated by the enzyme 'iodotyrosine dehalogenase' and returned to the thyroid iodide pool. A defect in this system results in cretinism from a failure of iodotyrosines to deiodinate.

Lack of iodide-concentrating mechanism Stanbury and Chapman (1960) have described a patient lacking the iodide concentrating mechanism who was unable to concentrate iodide in the thyroid, saliva, or gastric juice. The gland contained a small amount of proteinbound iodide which probably entered by diffusion. The patient was treated with potassium iodide. This case appears to indicate that there is a difference between the concentration of the iodide and the conversion to elemental iodine in the thyroid gland (stage 1, Fig. 8).

Familial goitre from failure to form organic iodine In 1950 Stanbury and Hedge reported a case of cretinism and goitre in a girl of 15 . She had developed normally until the age of 6 months and thereafter showed marked retardation. Signs of cretinism were noted at the age of 1 year and a goitre was noticed at the age of 7 . The patient was one of a family of seven children; the three older children were normal, the next four were cretins. Other cases have been described. Schultz, Flink, 
Kennedy, and Zieve (1957) described a 34-year-old cretin with a huge lobular thyroid who had the same enzymatic defect. The defect is probably transmitted as an autosomal recessive.

All the patients described will release labelled iodine from the thyroid gland when given potassium thiocyanate; the majority have been severe cretins with retarded structural and mental development. Normally no accumulated iodine can be released from the thyroid by potassium thiocyanate. The defect in these patients is one of failure to form organic iodine (stage II, Fig. 8) and then there is compensating hypertrophy of the gland. McGirr (1960) classified this as a defect in peroxidase.

Cretinism with failure of condensation of iodotyrosines Stanbury, Ohela, and Pitt-Rivers (1955) described a 25-year-old woman who showed retarded development and had a goitre. Evidence of cretinism had appeared at the age of 4 years with retarded growth and thick, dry skin. At the time of her admission the thyroid gland was enlarging. Histology of the gland removed at a subtotal thyroidectomy showed a multinodular goitre with extreme hyperplasia and no colloid formation. There were two consanguineous marriages in the family and a sister four years older suffered from an identical condition. Labelled iodine rapidly accumulated in the gland but was not discharged by potassium thiocyanate. Chromatographic analysis of the serum showed thyroxine and triodotyrosine in the blood but not in the thyroid gland. Excessive amounts of mono- and di-iodotyrosine were found in the gland. The simplest explanation of the defect is that there was a failure of coupling to form triiodothyronine and thyroxine in the thyroid gland (stage III, Fig. 8).

Cretinism from failure of iodotyrosine to deiodinate In 1953 McGirr and Hutchison reported 12 patients who were cretins and hypothyroid. Patients with this type of disease develop myxoedema or goitre before the age of 3, and they are mentally and physically retarded. The thyroid shows variable pathological changes; some areas are characteristic of colloid goitre, other areas have no colloid, and yet other areas show fibrosis. The subjects have excessive amounts of mono- and di-iodotyrosine in the blood. If these substances are given in a labelled form to patients after thyroidectomy or receiving thyroid the labelled iodotyrosine can be recovered quantitatively from the urine. The failure to deiodinate the iodotyrosines has been demonstrated in thyroid tissue (stage IV, Fig. 8) removed at operation, and also in liver, kidney, and other organs. The loss of iodine from continuous excretion is sufficient to prevent the formation of adequate amounts of thyroxine.
It has been suggested that there is also a defect of coupling in these patients but significant amounts of labelled tri-iodothyronine and thyroxine can be detected in their blood. The intensely hyperplastic glands are thought to secrete hormone precursors as fast as they are formed. The defect can be overcome if sufficient iodine is provided (Stanbury, 1961).

The genetics of this condition have been studied thoroughly in a group of itinerant Scottish tinkers in which intermarriage within the group was extremely frequent. A study of the family tree shows that this form of cretinism with goitre behaves as a simple autosomal recessive gene. It is probable that the cases are homozygous; relatives of cases described in Holland had defective di-iodotyrosine dehalogenase activity and were probably heterozygotes.

Cretinism with iodinated polypeptides in the serum These patients are characterized by the appearance in blood of iodinated amino-acids which are linked to peptides and are not extractable in acid butanol as are the iodinated thyronines which normally appear in peripheral blood. Stanbury and McGirr (1957) have described two sisters who were mentally retarded, hypothyroid, and had large goitres. Since then other cases have been described. The patients show hypothyroidism and no butanol extractable 131I-labelled component in peripheral blood, although in some cases it was found in urine.

Hydrolysis of the circulating component gave mono and di-iodotyrosines, tri-iodothyronine, and thyroxine. It may be that there is a defect in the synthesis of thyroglobulin, which may be comparable to the genetic control of haemoglobin synthesis, a defect in the degradation of thyroglobin or in the enzymes controlling the degradation. At present it is not possible to define the abnormality. This may be an abnormality of stage V (Fig. 8).

There are insufficient cases to define the mode of inheritance but the reported occurrence in two brothers and in two sisters suggests that the disease is hereditary.

THE ADRENOGENITAL SYNDROME The adrenogenital syndrome is usually manifested by pseudohermaphroditism of females and premature virilization of males and may occur spontaneously or as result of 2 adrenal or gonadal tumours. The syndrome is 0 caused by heritable defects in the biosynthesis of $\underset{\mathbb{D}}{\overparen{D}}$ steroids by the adrenal glands. These defects result $\stackrel{\mathscr{P}}{+}$ directly and indirectly in the overproduction of 7 certain steroids, some of which are androgenic. The cardinal sign is virilization but the clinical manifestations depend on the genetic sex, the age at onset, and the type and degree of the metabolic defect.

The patients can be divided into four groups: 


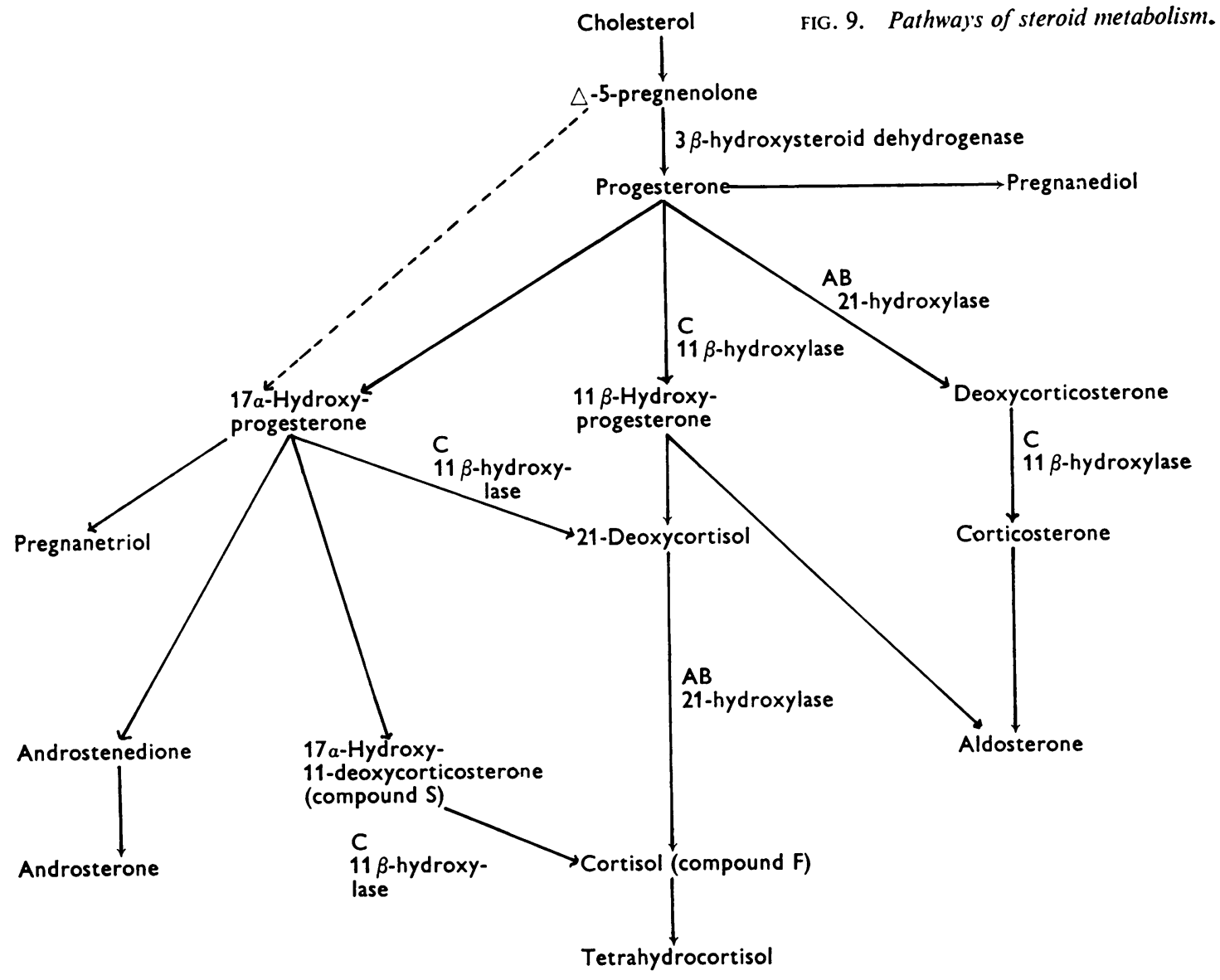

A Virilism, partial block 21-hydroxylase

B Virilism with adrenocortical insufficiency, more complete block 21-hydroxylase

C Virilism with hypertension, block $11 \beta$-hydroxylase

1 virilization, 2 virilization with adrenocortical insufficiency, 3 virilization with hypertension, and 4 virilization with adrenocortical insufficiency and hypertension.

Virilism The age of onset of virilization is most commonly prenatal but is probably not before the fifth month of development. Females exhibit a variable degree of malformation of the clitoris; virilization likewise takes place in males. Both sexes show accelerated somatic development; the epiphyses close early, and a deficit in growth results. Pubic hair may appear in the second year; in the male the testes remain small and immature. The females usually have amenorrhoea accompanying progressive virilization marked by male muscular development, male hair distribution, growth of beard and often temporal or frontal baldness. Breast development is slight and the voice is lowered in pitch. When the adrenogenital syndrome is not present at birth but occurs in the prepubertal period it is almost always due to an adenoma or adenocarcinoma of the adrenal cortex.

The adrenogenital syndrome can be distinguished from other forms of pseudohermaphroditism and virilism by the presence of diffuse adrenocortical hyperplasia and large quantities of androgenic ketosteroids in the urine. Initially treatment was directed against these, for example, by partial adrenalectomy.

Wilkins, Lewis, Klein, and Rosemberg (1950) administered cortisone to a female hermaphrodite with virilizing adrenal hyperplasia and found that the urinary ketosteroids fell. Bartter, Albright, Forbes, Leaf, Dempsey, and Carroll (1951) found that A.C.T.H. stimulated the production of 17ketosteroids in these patients but did not produce 
an immediate potassium loss or sodium retention, and as a result they suggested that the primary defect is decreased production of the sugar hormone by the adrenal cortex, thus the amounts of A.C.T.H. and of androgen were increased.

In 1953 Jailer suggested that hydroxylation of 17-hydroxyprogesterone at C-11 and C-21 to hydrocortisone was impaired. All evidence now indicates that in the most common form of the syndrome there is a partial block in the hydroxylation of C-21. Blood 21-hydroxycorticosteroids and urinary metabolites of hydrocortisone are decreased. The blood A.C.T.H. is increased and this stimulates the gland to produce large quantities of steroids that cannot be hydroxylated at C-21. Since pregnanetriol is the major corticosteroid metabolite in the urine of untreated patients, it has become a valuable asset in diagnosing the adrenogenital syndrome. Pregnanetriolone is always present in the urine of congenital adrenal hyperplasia, and unlike pregnanetriol, is absent in cases of adrenal carcinoma so far examined.

The unusual urinary steroids are products of alternative routes of metabolism of compounds of which the major routes are blocked in this syndrome. It is likely that part of the increased 17-ketosteroids in this syndrome is derived from $17 \alpha$-hydroxyprogesterone. Pregnanetriolone reflects the large quantities of 21-deoxycortisol which accumulate below the block. The virilization characteristic of this disease is due to $C_{19}$ steroids which can be derived from 17-hydroxyprogesterone. Most of the patients do not have adrenal insufficiency, as increased stimulation by A.C.T.H. probably provides sufficient hydrocortisone. Further evidence that 21-hydroxylation is not totally impaired is shown by the increase in blood and urine corticoids after stimulation with A.C.T.H.

In view of the large amounts of pregnanetriol and 17-ketosteroids excreted relative to decreased or normal amounts of hydrocortisone, it seems there is impaired conversion of $17 \alpha$-hydroxyprogesterone to hydroxycortisone. Bongiovanni (1958) showed that adrenal glands from two patients with the adrenogenital syndrome contained neither compound S (17hydroxy-11-desoxycorticosterone) nor cortisol but there was increased 17-hydroxyprogesterone. Homogenates of these glands did not form 21-hydroxylated steroids. The ability to convert to 11 -hydroxylate 17-hydroxy-11-desoxycorticosterone (compound S) to cortisol was not impaired. These observations support the concept of defective 21-hydroxylation and unimpaired 11-hydroxylation in this disease.

The inheritance is consistent with an autosomal recessive gene, which, when homozygous, produces the syndrome. The fact that the disease affects a single generation is also consistent with a homo- zygous recessive character. Females appear to be predominant over males but this could be explained by the greater ease of diagnosis in females.

Virilism with adrenocortical insufficiency In approximately half the patients with congenital adrenal virilism there are associated disturbances of salt and water metabolism. Characterized by urinary loss of sodium and chloride, these abnormalities appear by the age of 7 weeks in almost all the affected infants. The infants are apathetic, they vomit, they have diarrhoea, and they are dehydrated. They tend to go into circulatory collapse. It may be difficult to diagnose the condition in males because they may have normally sized genitalia at birth.

In this group no tetrahydrocortisol is excreted and there is more urinary pregnanetriol than in the previous group. This indicates that the block in 21-hydroxylation is more nearly complete. The adrenal gland cannot produce enough 21-hydroxylated steroids to prevent salt loss and signs of adrenocortical insufficiency. In some patients salt loss only occurs in superimposed stress such as infection.

An alternative explanation is that there is a saltdiuretic hormone produced by the overstimulated gland. Klein, Taylor, Papadatos, Laron, Keele, Fortunato, Byers, and Billings (1958) have shown the presence of a substance in the urine of infants with congenital adrenal hyperplasia that causes sodium excretion in rats. It may be that, on the basis of synthetic steroid studies, salt metabolism can be affected by a progesterone-like compound.

Virilism with hypertension Another group of patients with the adrenogenital syndrome have, in addition to progressive virilization, hypertension which can be severe enough to produce cardiomegaly and heart failure. The major virilizing forms and the hypertensive forms appear to be inherited differently. Both forms were never observed simultaneously in one family in a survey of 18 families.

The defect in the hypertensive form is different $\frac{D}{O}$ from the major virilizing form. Eberlein and Bongiovanni (1955) found an excess of 17-hydroxy- $\sigma$ 11-desoxycorticosterone (compound $S$ ) and the $N$ tetrahydroderivative in the blood but no 11- N oxygenated 17-ketosteroids were detected and there was a small amount of pregnanetriol excreted relative to the 17-ketosteroids. The defect can be explained by a defect in hydroxylation of C-11. It is generally thought that deoxycorticosterone is responsible for the hypertension in this disease.

The above descriptions associate the clinical syndromes with specific enzyme defects but evidence $\frac{\sim}{\mathbb{D}}$ is accumulating that obscures the individual nature $\triangle$ of each syndrome. Bartter and Pronove (1960) studied three infants with the adrenogenital syn- $\delta$ 
drome associated with adrenal insufficiency and hypertension. This would suggest that there may be a single genetically determined defect resulting in the absence of a cofactor or enzyme required for both 21- and 11-hydroxylation. It is probable that there are several substrate specific enzymes which determine which of several 11-deoxy substrates will be hydroxylated. The oxygen used comes from the atmospheric oxygen and N.A.D.P. and is involved in the system. The N.A.D.P. may be used only secondarily, for example, to reduce a metal in the enzyme after its oxidation with oxygen. Thus 11-hydroxylation is a complex and as yet unknown process. It is probable that 21 -hydroxylation is also complex; the genetically determined defect is probably in one of the cofactors for the reaction.

Another type of defect has been reported by Bongiovanni (1961) in which there was a deficiency of $3 \beta$-hydroxy dehydrogenase. The condition was lethal and a group of $3 \beta$-hydroxy $\triangle-5$-steroids predominated in the urine.

\section{DISTURBANCES IN PIGMENT METABOLISM}

THE HEREDITARY METHAEMOGLOBINAEMIAS This is a rare condition, of which the major feature is a diffuse persistent slate-gray cyanosis which is present from early infancy and unassociated with clubbing of the fingers or significant cardiac murmurs. Methaemoglobin comprises 20 to $50 \%$ of the total haemoglobin. Compensating polycythaemia and associated reticulocytosis are occasionally seen. The blood is chocolate coloured and fails to turn red on oxygenation due to excessive amounts of methaemoglobin. The increased concentration of methaemoglobin occurs in the absence of any exogenous methaemoglobin-producing substances. Methaemoglobinaemia is not a single disease but a group of diseases which may be due to formation of an abnormal methaemoglobin resistant to reduction; a deficiency in the erythrocyte reducing system with accumulation of normal methaemoglobin; or abnormal endogenous production of oxidizing substances.

Methaemoglobinaemia associated with abnormal methaemoglobins In 1948 Hörlein and Weber reported a type of methaemoglobinaemia which was transmitted as a dominant. The methaemoblogin had a different spectral absorption curve which they showed was due to a globin abnormality. Gerald (1958) has pointed out that electrophoresis of haemolysates in this condition shows the presence of abnormal $\mathrm{Hb}$ M-type pigments. These have been purified and studied spectroscopically and have been classified as $\mathrm{Hb}$ Мв (Boston), $\mathrm{Hb}$ Ms (Saskatoon), and $\mathrm{Hb}$ Мм (Mineapolis). The methaemoglobins are oxidation products of these abnormal haemoglobins.
It has been postulated that a new reactive group occurs in the globin which is capable of complexing ferric iron; this could be at a point of alteration in the amino-acid sequence, as has been described for the abnormal haemoglobins.

No abnormality has yet been described in the erythrocyte enzyme systems. The life span is normal and there is no reticulocytosis.

Methaemoglobinaemia associated with a deficiency of the methaemoglobin-reducing system Gibson (1954) studied several families with methaemoglobinaemia and demonstrated a defect in the enzyme system which is normally responsible for maintaining haemoglobin in the reduced state. In the normal red cell methaemoglobin reduction is probably linked to glycolysis through N.A.D. Certain autoxidizable dyes, such as methylene blue, are capable of accelerating the reduction of methaemoglobin. In the presence of the proper substrate, methylene blue activates the hexose monophosphate shunt. Most investigators believe that the reaction between methaemoglobin and the reduced pyridine nucleotides is an enzymatically controlled step. This has been termed 'methaemoglobin reductase' and it may catalyse the reduction of methaemoglobin with N.A.D.P.H. and N.A.D.H. Scott and Griffith (1959) have shown that there is an enzyme in normal red cells which reduces methaemoglobin and has a preference for N.A.D. Gibson (1954) considered that there was a deficiency of the enzyme catalysing the reduction of methaemoglobin by N.A.D. in this type of congenital methaemoglobinaemia. Scott and Griffith (1959) have shown that there is a deficiency of an N.A.D-dependent enzyme in haemolysates from patients with hereditary methaemoglobinaemia on the basis of the reaction between 2,6-dichlorobenzenone-indophenol and N.A.D.H. This type of congenital methaemoglobinaemia is transmitted as a recessive character.

Congenital methaemoglobinaemia due to excess of endogenous oxidizing substances Fishberg (1948) described a case which may be of this type. The patient excreted large amounts of benzoquinoneacetic acid in the urine, the amount excreted varying roughly with the methaemoglobin level in the blood. Administration of ascorbic acid abolished the methaemoglobinaemia and the excretion of benzoquinoneacetic acid.

THE PORPHYRIAS Porphyria has aroused interest among clinicians and laboratory workers because of the unusal clinical manifestations with which it is associated and the relative ease with which the porphyrins can be identified, even in small amounts. Recent reviews on the porphyrias include those of Schmid (1960) and Waldenström (1957). In this 


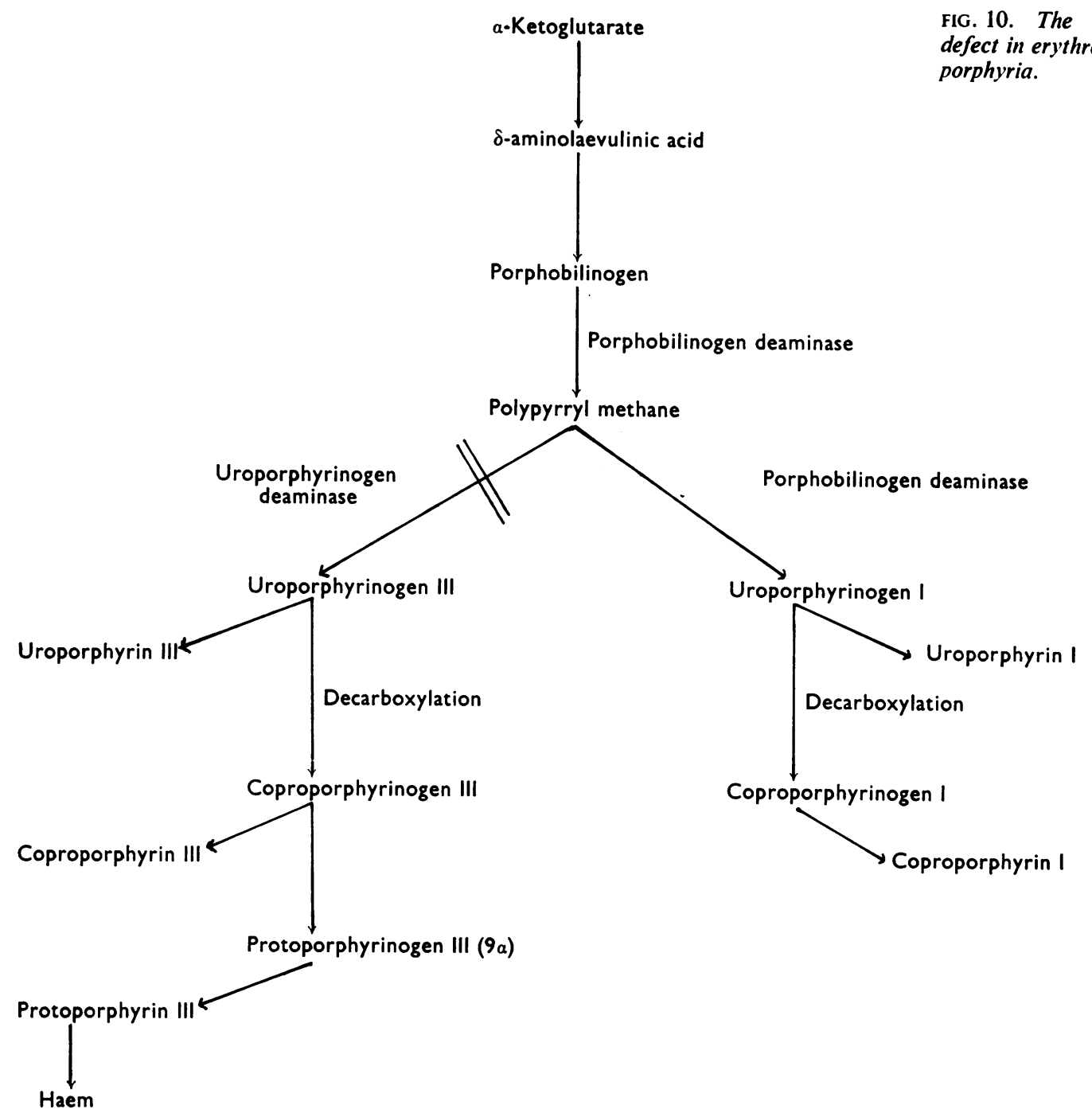

FIG. 10. The defect in erythropoietic a-Ketoglutarate 
deaminase and uroporphyrinogen isomerase. It would appear that either overactivity of porphobilinogen deaminase or a defect in uroporphyrinogen isomerase would account for the defect. The primary defect involves the production of porphyrins of the type $I$ isomer for which the body has no use. The defect appears confined to the haemopoietic system and may involve only part of the erythroid cells.

Its occurrence in more than one child in the same family and the ratio of $1: 3$ for affected and unaffected siblings of both sexes suggest that the abnormality is inherited as a Mendelian autosomal recessive trait. The penetrance of the abnormal gene appears complete. The lack of increased porphyrin excretion in parents and normal siblings of patients suggests that individuals who are heterozygous for the trait do not exhibit the metabolic abnormality.

HEPATIC FORMS In congenital erythropoietic porphyria the metabolic defect can be traced to the developing red cells, but in the other forms of human porphyria no such defect is found. In these forms the liver is the only organ containing large amounts of porphyrins and porphyrin precursors; hepatic function is frequently impaired.

In this review we shall consider the different types of hepatic porphyria as they appear in genetically homogenous groups. This classification does not take into account the precise metabolic defect as it is not yet known.

The Swedish type This was extensively investigated by Waldenström in 1937. The syndrome is characterized by abdominal and neurological symptoms which are frequently intermittent. The abnormality is believed to be inherited as a Mendelian dominant but afflicted individuals may be free of symptoms. Present methods fail to show an abnormality in asymptomatic persons who are genetically certain carriers.

The major biochemical defect in this form is the overproduction of the porphyrin precursors $\delta$ aminolaevulinic acid and porphobilinogen. There is little information to support the idea that the biosynthesis of some haem-containing compound is blocked and the increases in the pyrroles attempt to compensate for this. A second hypothesis which suggests a defect of formation or metabolism of $\delta$-aminolaevulinic acid is consistent with the findings studying the pool size and disposition of $\delta$-aminolaevulinic acid and porphobilinogen. The primary disturbance probably does not involve porphyrin metabolism but occurs at the level of pyrrole biosynthesis which is interrelated with the tricarboxylic acid cycle.

South African type Dean and Barnes (1959) studied a large group of porphyric patients in the white population in South Africa. These patients can be traced to a pair of early settlers in South Africa. Many of the patients have skins sensitive to sunlight and slight mechanical trauma. Cutaneous manifestations are often the only symptoms in men who feel well throughout life. In some members acute attacks of abdominal pain occur; women are more likely to have abdominal pain and skin sensitivity is usually slight. Acute attacks can occur, perhaps with peripheral and bulbar paralysis which may produce respiratory failure. In many persons the disease is latent throughout life. In this form the characteristic finding is the excretion of large amounts of coproporphyrin and protoporphyrin in the faeces. Faecal excretion is elevated even though patients may be in clinical remission and may be asymptomatic throughout life. During acute episodes urinary porphyrin is increased and the urine contains large amounts of $\delta$-aminolaevulinic acid and porphobilinogen while during remission the excretion of these compounds returns to normal limits. This type is different from the Swedish type by the fact that large amounts of copro-and protoporphyrin are excreted in the faeces. The South African studies indicate that the defect is inherited as a Mendelian dominant trait.

Schmid (1960) reviewed the other reported cases of porphyria in which the metabolic defect and the mode of inheritance is less clear. It is difficult to classify these families at present; for example, Holti, Rimington, Tate, and Thomas (1959) have described a porphyric family in which the defect is a dominant trait. The disease was noticed in a young woman who developed bullous skin lesions after delivery, and nine other members of the family had chemical evidence of porphyria in that the faecal excretion of coproporphyrin and protoporphyrin was increased. The urinary porphyrins were normal or only slightly increased. This also differs from the South African type in that in the South African type large amounts of $\delta$-aminolaevulinic acid and porphobilinogen were excreted coinciding with the acute abdominal and neurological manifestations. It is probable that this family is different from the South African and Swedish types.

As can be seen the nature of the metabolic defect of the hepatic types has not yet been determined and it is in this field that future study should lie.

HYPERBILIRUBINAEMIA Conjugation of bilirubin by the liver is essential for excretion of the pigment. The passage of bilirubin through the liver cell involves several stages, and various type of congenital jaundice have been described, related to each of these stages. 
Jaundice due to disturbance of the transport mechanism This syndrome has been called Gilbert's disease, hereditary non-haemolytic bilirubinaemia, familial non-haemolytic jaundice, or constitutional hepatic dysfunction. The syndrome is characterized by a mild, chronic, apparently non-haemolytic hyperbilirubinaemia with unconjugated pigment in the blood (Meulengracht, 1947). This syndrome has a variable course but often the jaundice is observed coincidentally with a routine examination or during some other illness.

In this syndrome bilirubin uptake by the liver (Klatskin, 1961) is defective. The pigment in the blood is unconjugated and the bile pigment content of the bile is similar to normal bile. Arias, Lowy, and London (1958), using needle biopsy specimens and a very sensitive assay method with 4-methyl umbelliferone, claimed to show a decrease in the glucuronyl transferase in the liver. The glucuronidation system using $\mathrm{N}$-acetyl-p-aminophenol and menthol in vivo is normal. Schmid and Hammaker (1959) believed the abnormality to be due to defective bilirubin transport from the plasma to the site of conjugation in the liver cell. In Britain 'Gilbert's syndrome' describes those patients who have a defect in bilirubin uptake.

The occurrence of unexplained hyperbilirubinaemia in more than one member of a family has repeatedly been reported, and the investigations suggest that the syndrome is genetically controlled and may be transmitted as a Mendelian dominant. It has been suggested that this syndrome represents the heterozygous form of congenital non-haemolytic jaundice (Crigler-Naijar syndrome) or that Gilbert's syndrome represents a milder degree of the same defect as the Crigler-Najjar syndrome. Against this is the observation that patients with Gilbert's syndrome form glucuronides at normal rates and siblings of patients with congenital non-haemolytic jaundice do not have mild hyperbilirubinaemia.

Jaundice due to disturbance of bilirubin conjugation Before bilirubin can be excreted in the bile it must be converted to a water-soluble conjugate with glucuronic acid, bilirubin diglucuronide; this process takes place in the liver. The glucuronic acid comes from uridine diphosphate glucuronic acid; the reaction is catalysed by glucuronyl transferase, a microsomal enzyme. Glucuronyl transferase is deficient in the newborn animal (Lathe and Walker, 1958); as the newborn matures the activity of the enzyme increases, ultimately attaining adult levels within a few weeks. A deficiency of glucuronyl transferase can be a cause of neonatal jaundice.

Congenital familial non-haemolytic jaundice (Crigler-Najjar syndrome) was described by Crigler and Najjar in 1952. In three related families six infants were found in whom severe jaundice appeared about two days after birth and persisted throughout life. All but one developed severe changes in the central nervous system resembling kernicterus and five died before they were 15 months old. Other cases have been described by Schmid (1960). Investigations show that these patients clear bromsulphthalein normally and that the gall bladder can be visualised normally by intravenous cholangiography. Only unconjugated bilirubin is found in the serum; the bilirubin tolerance is impaired and there is no evidence of excessive haemolysis.

It is probable that the defect in these cases is a lack of the enzyme, glucuronyl transferase. Jervis (1959) showed that a liver homogenate from a patient with the syndrome could not conjugate bilirubin in vitro. This would support the theory that the condition is due to a lack of, or an impairment of, glucuronyl transferase.

Crigler and Najjar (1952) showed that there was a definite familial pattern as six cases occurred in three related families. It is probable that the defect is inherited as a recessive trait. Childs, Sidbury, and Migeon (1959) fed sodium salicylate to the relations of three cases and found that glucuronide excretion was impaired. It may be that the gene is incompletely dominant for other glucuronide-forming compounds.

Jaundice due to disturbances of conjugated bilirubin excretion In 1954 Dubin and Johnson described a chronic benign intermittent jaundice in young people characterized by a raised serum bilirubin level which is mainly in the conjugated form. The liver is greenish black due to an excess of black granules in the liver cell. This pigment may be a lipofuscin and the granules may be altered lysosomes.

The syndrome can be familial (Wolf, Pizette, Richman, Dreiling, Jacobs, Fernandez, and Popper, 1960). Wolf and his colleagues found that the degree of liver pigmentation varied but the mode of inheritance is not yet known.

Rotor, Manahan, and Florentin (1948) described a type of jaundice similar to the Dubin-Johnson type but the liver was not pigmented. As in the DubinJohnson type of jaundice there is an increase in the conjugated bilirubin in the serum and the 210minute value for the level of bromsulphthalein is greater than the 45-minute value. The results suggest that the excretion of the conjugated pigment is 6 impaired. The jaundice occurs in several members $\overparen{D}$ of a family but the evidence is insufficient to deter- $\stackrel{\oplus}{+}$ mine whether the defect is genetically controlled.

\section{ABNORMALITIES OF PURINE METABOLISM}

GOUT Primary gout is a disorder of purine metabolism, the cardinal feature of which is hyperuric- 
aemia. It is pre-eminently a disorder of adult males and is characterized both by recurrent attacks of acute arthritis of unknown cause and by a chronic arthritis associated with deposits of urates in joints and other tissues.

The heritable nature of gout has been recognized since the time of Galen but it has only been included as an inborn error of metabolism in the last thirty years. The hesitancy was due to the idea that gout was not an error of metabolism but was based on an alternative and slightly divergent path of metabolism met with in a large part of the total population. Now that it has been classified as an inborn error of metabolism it can be seen that gout conforms to a well-defined clinical and metabolic pattern. These considerations apply to primary gout and not to the secondary types.

A family history of primary gout has been recorded in only 6 to $18 \%$ of cases but is enlarged when a study of hyperuricaemia is made. Asymptomatic hyperuricaemia is approximately five times as common as clinical gout in families of gouty persons. It is thought that penetrance of the presumed autosomal dominant is variably incomplete in different families; expressivity ranges from a relatively early appearance of fulminating symptoms to a long-delayed appearance of mild symptoms. There is a striking preponderance of males $(95 \%)$.

The considerations that apply to gout apply to inborn errors of metabolism in general. The spectrum of expression is presumed to be the result of a complex interaction of genetic, metabolic, and environmental influences (Gutman, 1959); the appearance of gout does not depend on the genetic endowment alone since it is the predisposition to gout, not gout itself, that is inherited.

Although inborn, no sign of gout is detectable until hyperuricaemia is found at puberty, especially in males, persisting in variable degree. Acute gouty arthritis appears at sporadic intervals, then tophaceous deposits form and the patient has joint symptoms between the acute attacks. Eventually chronic gouty arthritis, chronic gouty bursitis, renal impairment, and sometimes renal failure ('gouty kidney') develop.

Among other inborn errors of metabolism not apparent at birth, galactosaemia and alkaptonuria appear some days or weeks after birth and glycogen storage disease can occur some months after birth. Genetically transmitted hypercholesterolaemia can be considered similar to gout in that the cholesterol level does not rise until after puberty and symptoms do not appear until middle life.

The precipitation of attacks of acute gouty arthritis may be analogous to the crises in sickle cell anaemia or the abdominal crises in acute porphyria.
It is doubtful whether uric acid itself is the precipitating agent. The storage of uric acid in tophi is analogous to the storage of lipids, carbohydrate, and pigments in other 'storage' diseases; why cartilage is the site selected is unknown, but it also occurs in ochronosis. Uric acid is precipitated in the kidney itself and as stones in the lower parts of the renal tract; the factors causing precipitation include an increased concentration in the urine, infection, and a drop in the urinary $p \mathrm{H}$.

The cause of hyperuricaemia has been debated for many years and it seems probable that in gouty subjects there is an increased urate generation and a decreased urinary excretion (Wyngaarden, 1960). Gutman and Yü (1957) showed that $30 \%$ of gouty subjects excrete excessive amounts of urate in the urine. These authors considered that there is no evidence for excessive reabsorption from the kidney and that hyperuricaemia is due to excessive production of uric acid. In the hyperexcretors of uric acid overproduction of uric acid must occur but in most cases large amounts are excreted in the gut (Sorensen, 1959), also implying an overproduction of uric acid.

In the diseases previously considered, e.g., phenylketonuria and alkaptonuria, the abnormal metabolites are formed from intermediary compounds but uric acid is an end-point of metabolism. It was formerly thought that uric acid originated solely or largely from preformed exogenous or endogenous nucleic acids and that the hyperuricaemia of gout was due to excessive nucleic acid degradation.

Overincorporation of glycine or other precursors into uric acid is demonstrable in many cases of gout, and those subjects who excrete large amounts of uric acid have shown overincorporation of glycine. It is probable that overincorporation is more frequent than can be demonstrated by turnover studies. Overincorporation of precursors into uric acid appears to be due to a shunt pathway whereby a percentage of newly formed pyridine nucleotides is broken down to purine bases which are then oxidized to uric acid. It may be that there is a defect in the control of the production of phosphoribosylamine Jones, Ashton, and Wyngaarden (1962) demonstrated an increased specific activity in the ribose moiety of imidazoleaceticacid riboside after administration of ${ }^{14} \mathrm{C}$ glucose in certain gouty subjects. There was an increased turnover of phosphoribosyl pyrophosphate, suggesting a failure in control at an early site in purine synthesis. The hypothesis must account for an excessive production of urate and this is best explained by the idea that precursors of purines are deflected from competing pathways. The concept implies that the lack of enzyme in 


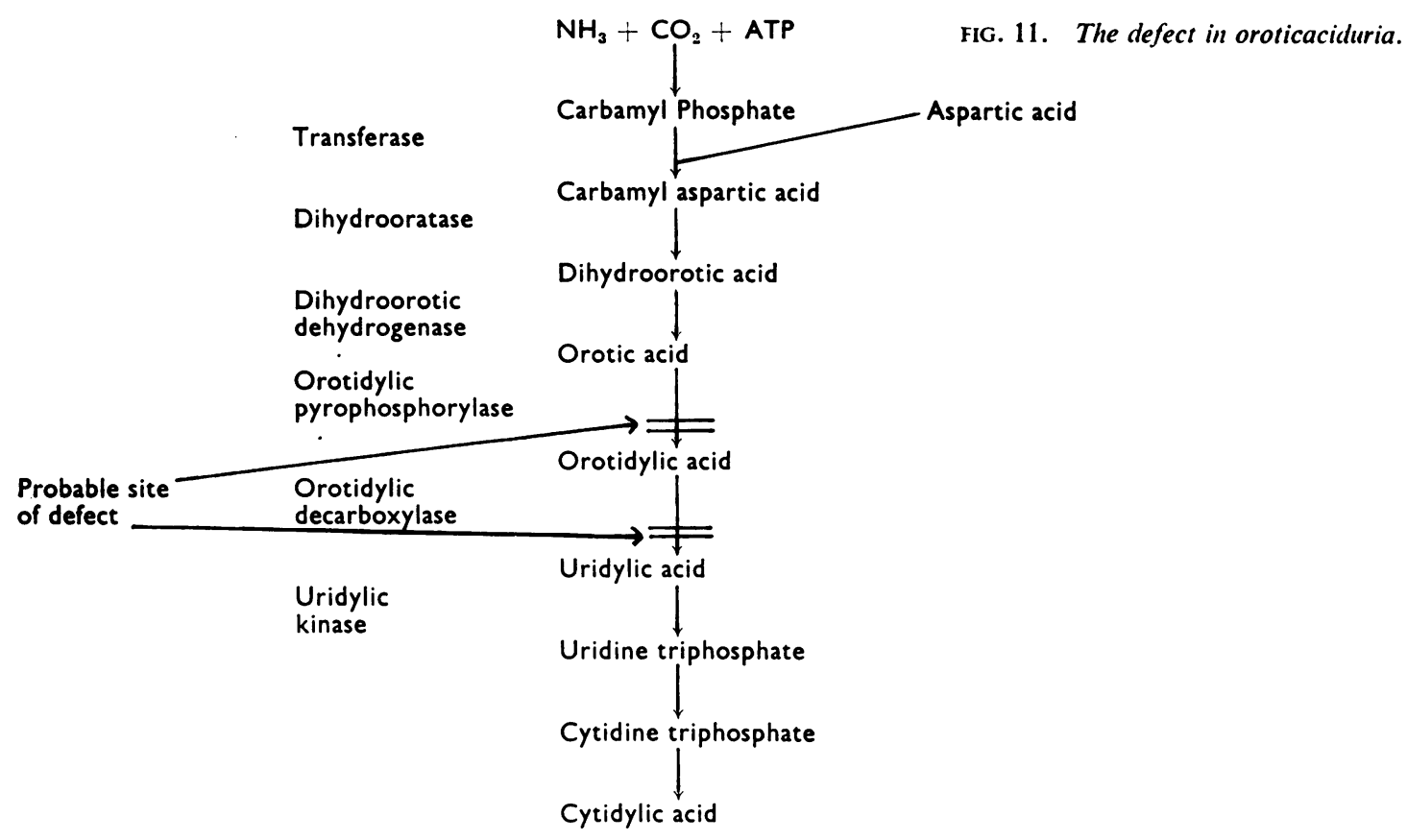

primary gout does not reside in the sequential reaction of purine biosynthesis but elsewhere.

The heredity factor in the hyperuricaemia of gout is well established; whether the hyperuricaemia is determined by an autosomal dominant with complete penetrance or by cumulative gene action is not yet known. It seems likely that different patterns of inheritance may occur.

XANTHINOSIS This is a rare disorder characterized by the excretion of very large amounts of xanthine in urine and the tendency to form renal stones.

Dent and Philpot (1954) described a girl of $4 \frac{1}{2}$ years with a clear renal stone. Analysis showed that the stone contained xanthine but no detectable uric acid and the patient had no detectable uric acid in the blood. Dickinson and Smellie (1959) reinvestigated the child, and, using specific enzymatic methods, showed that the plasma oxypurines were increased. Other cases of xanthine stones have been described but this is the only case that has been fully investigated biochemically.

Dent and Philpot suggested that gross xanthinuria, together with low levels of uric acid in the plasma and urine, may be due to a block in the oxidation of xanthine to uric acid or to the excessive excretion of xanthine preventing its conversion to uric acid. This may be due to a renal tubular defect preventing its reabsorption. Dickinson and Smellie (1959) suggested that both defects are present. It was suggested that the enzyme xanthine oxidase is almost entirely lacking, it would be expected that hypoxanthine would also be present in the plasma.

The genetic defects in xanthinuria are obscure, but investigation of the relatives has precluded an autosomal dominant mode of inheritance.

OROTICACIDURIA Huguley, Bain, Rivers, and Scoggins (1959) described a child in whom there was a refractory megaloblastic anaemia associated with the excretion of orotic acid in urine. From the age $\overline{-}$ of 3 months the child was chronically ill, had repeated respiratory infections and diarrhoea, the $\delta$ bone marrow was megaloblastic, and the urine $₹$ contained crystals of orotic acid. There was some $\frac{\text { ? }}{2}$ improvement in all features of the disease after the $>$ administration of steroids and almost complete clearing of evidence of the disease after the administration of uridylic and cytidylic acids.

The findings implied a defect in the pyrimidine $N$ synthetic pathway between orotic acid and orotidylic $\underset{\omega}{N}$ acid. A lack of orotidylic phosphorylase or orotidylic decarboxylase would account for the accumulation 6 of orotic acid. The fall in orotic acid excretion after $\stackrel{\complement}{\mathcal{D}}$ uridylic and cytidylic acid administration could be $\stackrel{\oplus ?}{?}$ ascribed to a negative feedback mechanism.

The parents were related and reduced levels of 0 both orotidylic pyrophosphorylase and orotidylic $\stackrel{\mathbb{\Omega}}{\Omega}$ decarboxylase in erythocytes of both parents and of $\stackrel{\odot}{\circ}$ two surviving siblings were found. It may be that thiso defect is of a recessive type. 


\section{PSEUDOCHOLINESTERASE DEFICIENCY}

Suxamethonium (succinyl dicholine) is a shortacting muscle relaxant. Its removal depends on the concentration of serum pseudo-cholinesterase. Lehmann and Ryan (1956) described a familial incidence of low pseudo-cholinesterase. Kalow (1959) has reviewed work in which it was shown that the serum enzymes of such patients differed from those of normals as determined by substrate affinities as well as by lessened sensitivity to inhibitors. The decreased sensitivity to dibucaine (nupercaine) was determined; the results fell into three groups which best fit the model of two autosomal allelic genes without dominance, yielding normal, atypical, and mixtures of the two enzymes. It was found that an inhibitor in potato peel distinguished the three groups and related well to the dibucaine inhibitions. Inhibition studies indicate that the difference at the anionic site could be because of a relatively weak effective charge in the atypical enzyme. In this inborn error the cholinesterase is not present in smaller amounts but has rather different catalytic properties than normal.

\section{CONCLUSION}

In this review we have indicated those diseases that can be called inborn errors of metabolism. This list is not complete because we have left out those diseases which are either due to defective tubular reabsorption in the kidney or to impaired absorption from the gut. These hereditary diseases demonstrate the importance of the biochemical approach in clinical medicine. The hereditary make-up of the organism determines the potentiality, but other factors, for example the environment, play a part. For instance, the haemolytic anaemia due to glucose6-phosphate dehydrogenase deficiency only appears when some factor intervenes to oxidize the cell glutathione; the galactosaemic infant becomes ill when fed on galactose. This combination of genetic and environmental factors may play an important part in our understanding of other disease, for example, diabetes. Although the diseases we have described are for the most part rare, it is probable that in the next decade others will be found, and, more important, some of the commoner diseases will be better understood by the application of methods of investigation similar to those outlined.

\section{ADDENDUM}

HOMOCYSTINURIA Carson, Cusworth, Dent, Field, Neill, and Westall (1963) have described homocystinuria in two mentally defective sibs. Homo- cystine was also found in the plasma. The children's mother and the two children have an impaired methionine tolerance, probably indicating an inherited defect of methionine metabolism.

I should like to thank Professor N. H. Martin for his help and advice in the preparation of this review, and also to acknowledge the help given by the British Empire Cancer Campaign.

\section{REFERENCES}

Allan, J. D., Cusworth, D. C., Dent, C. E., and Wilson, V. K. (1958). Lancet, 1, 182.

Andersen, D. H. (1956). Lab. Invest., 5, 11.

Anderson, E. P., Kalckar, H. M., and Isselbacher, K. J. (1957). Science, $125,113$.

Aponte, G. E., and Fetter, T. E. (1954). Amer. J. clin. Path., 24, 1363. Archer, H. E, Dormer, A. E., Scowen, E. F., and Watts, R. W. E. (1958). Ann. hum. Genet., 22, 373.

Arias, I. M., Lowy, B. A., and London, I. M. (1958). J. clin. Invest., 37, 875.

Asatoor, A. M., Lacey, B. W., London, D. R., and Milne, M. D. (1962). Clin. Sci., 23, 285.

Auerbach, V. H., DiGeorge, A. M., Baldridge, R. C., Tourtellotte, C. D., and Brigham, M. P. (1962). J. Pediat., 60, 487.

Bartter, F. C., Albright, F., Forbes, A. P., Leaf, A., Dempsey, E., and Carroll, E. (1951). J. clin. Invest., 30, 237.

$\longrightarrow$, and Pronove, P. Personal communication. Quoted by G. M. Tomkins, and J. S. McGuire (1960). In The Metabolic Basis of Inherited Disease, edited by J. B. Stanbury, J. B. Wyngaarden, and D. S. Fredrickson, p. 639. McGraw-Hill, New York.

Beadle, G. W. (1945). Chem. Rev., 37, 15.

Boedeker. (1859). Z. rat. Med.,7, 130.

Bongiovanni, A. M. (1958). J. clin. Invest., 37, 1342.

(1961). J. clin. Endocr., 21, 860.

Bozian, R. C., and Touster, O. (1959). Nature (Lond.), 184, 463.

Calderbank, A., Kent, P. W., Lorber, J., Manners, D. J., and Wright, A. (1960). Biochem. J., 74, 223.

Carson, M. J., and Koch, R. (1955). J. Pediat., 47, 161.

Carson, N. A. J., Cusworth, D. C., Dent, C. E., Field, C. M. B., Neill, D. W., and Westall, R. G. (1963). Arch. Dis. Childh. In the press.

Carson, P. E., Flanagan, C. L., Ickes, C. E., and Alving, A. S. (1956). Science, 124, 484.

Chambers, R. A., and Pratt, R. T. C. (1956). Lancet, 2, 340.

Childs, B., Sidbury, J. B., and Migeon, C. J. (1959). Pediatrics, 23, 903.

—, Nyhan, W. L.,Borden, M., Bard, L., and Cooke, R. E. (1961). Ibid., 27, 522.

Cordes, W. (1926). Rep. un. Fruit Co. med. Dept. N.Y., 15, 66. Quoted by E. Beutler (1960). In The Metabolic Basis of Inherited Disease, edited by J. B. Stanbury, J. B., Wyngaarden, and D. S. Frederickson, p. 1031. McGraw-Hill, New York.

Cori, G. T., and Cori, C. F. (1952). J. biol. Chem., 199, 661.

- (1957). Mod. Probl. Pädiat., 3, 344.

Crawhall, J. C., Scowen, E. F., and Watts, R. W. E. (1959). Lancet, 2, 806.

Crigler, J. F. Jr., and Najjar, V. A. (1952). Pediatrics, 10, 169.

Crumpler, H. R., Dent, C. E., Harris, H., and Westall, R. G. (1951). Nature (Lond.), 167, 307.

Cusworth, D. C., and Dent, C. E. (1960). Biochem. J., 74, 550.

Dancis, J., Levitz, M., Miller, S., and Westall, R. G. (1959). Brit. med. J., 1, 91.

,-- and Westall, R. G. (1960). Pediatrics, 25, 72.

Davies, H. E., and Robinson, M. J. (1963). Arch. Dis. Childh., 38, 80.

Dean, G., and Barnes, H. D. (1959). S. Afr. med. J., 33, 246.

Dent, C. E. (1956). In Bone Structure and Metabolism, Ciba Foundation Symposium, edited by G. E. W. Wolstenholme and C. M. O'Connor, p. 266. Churchill, London. and Philpot, G. R. (1954). Lancet, 1, 182.

—, and Rose, G. A. (1951). Quart. J. Med., 20, 205.

_, and Westall, R. G., (1961). Arch. Dis. Childh., 36, 259.

Dern, R. J., Weinstein, I. M., Le Roy, G. V., Talmage, D. W., and Alving, A. S. (1954). J. Lab. clin. Med., 43, 303. 
Dickinson, C. J., and Smellie, J. M. (1959). Brit. med. J., 2, 1217. di Sant' Agnese, P. A., Andersen, D. H., and Mason, H. H. (1950). Pediatrics 6, 607 , and Metcalf, K. M. (1962). J. Pediat., 61, 438.

Dubin, I. N., and Johnson, F. B. (1954). Medicine (Baltimore), 33, 155.

Dubois, R., Loeb, H., Ooms, H. A., Gillet, P., Bartman, J., and Champenois, A. (1961). Helv. paediat. Acta, 16, 90.

Eberlein, W. R., and Bongiovanni, A. M. (1955). J. clin. Endocr., 15, 1531.

—, Illingworth, B. A., and Sidbury, J. B. (1962). Amer. J. Med., 33, 20.

Elder, T. D., Segal, S., Maxwell, E. S., and Topper, Y. J. (1960). Fed. Proc., 19, 53.

Felix, K., Leonhardi, G., and Glasenapp, I. V. (1951). Hoppe-Seylers Z. physiol. Chem., 287, 141.

Fishberg, E. H. (1948). J. biol. Chem., 172, 155.

Fitzpatrick, T. B. (1960). In The Metabolic Basis of Inherited Disease, edited by J. B. Stanbury, J. B. Wyngaarden, and D. S. Frederickson, p. 428. McGraw-Hill, New York.

Folling, A. (1934). Hoppe-Seylers Z. physiol. Chem., 227, 169.

Forbes, G. B. (1953). J. Pediat., 42, 645.

Fraser, D. (1957). Amer. J. med., 22, 730

- , Vendt, E. R., and Christie, F. H. (1955). Lancet, 1, 286.

Freedberg, I. M., Feingold, D. S., and Hiatt, H. H. (1959). Biochem. biophys. Res. Commun., 1, 328.

Froesch, E. R., Prader, A., Wolf, H. P., and Labhart, A. (1959). Helv paediat. Acta, 14, 99.

Garrod, A. E. (1902). Lancet, 2, 1616.

(1909). Inborn Errors of Metabolism. Frowde, London.

Gerald, P. S. (1958). Blood, 13, 936.

Ghadimi, H., Partington, M. W., and Hunter, A. (1961). New Engl. J. Med., 265, 221.

Gibson, Q. H. (1954). Biochem. Soc. Symp., 12, 55.

Gierke, E. von (1929). Beitr. path. Anat., 82, 497.

Gutman, A. B. (1959). Bull. N. Y. Acad. Med., 35, 419.

- , and Yü, T. F. (1957). Amer. J. Med., 23, 600.

Harris, H., Penrose, L. S., and Thomas, D. H. H. (1959). Ann. hum. Genet., 23, 442.

Hartmann, A. F., Wohltmann, H. J., Purkerson, M. L., and Wesley, M. E. (1962). J. Pediat., 61, 165.

Hers, H. G. (1959). Rev. int. Hépat., 9, 35. (1961). Chem. Weekblad., 57, 437.

Hiatt, H. H. (1958). Biochim. biophys. Acta (Amst.), 28, 645.

Hockwald, R. S., Arnold, J., Clayman, C. B., and Alving, A. S. (1952). J. Amer. med. Ass., 149, 1568.

Holzel, A., Mereu, T., and Thomson, M. L. (1962). Lancet 2, 1346.

- Schwarz, V., and Sutcliffe, K. W. (1959). Ibid., 1, 1126.

Holti, G., Rimington, C., Tate, B. C., and Thomas, G. (1959). Quart. J. Med., 27,1 .

Hörlein, H., and Weber, G. (1948). Dtsch. med. Wschr., 73, 476.

Huguley, C. M. Jr., Bain, J. A., Rivers, S. L., and Scoggins, R. B. (1959). Blood, 14, 615.

Huisman, T. H. J., and Jonxis, J. H. P. (1957). Arch. Dis. Childh., 32, 77.

Illingworth, B., and Cori, G. T. (1952). . biol. Chem., 199, 653.

Illingworth, B., and Cori, G. T. (1956). Ibid., 218, 123.

Isselbacher, K. J., Anderson, E. P., Kurahashi, K., and Kalckar, H. M. (1956). Science, 123, 635 .

Jailer, J. W. (1953). Bull. N. Y. Acad. Med., 29, 377.

Jervis, G. A. (1953). Proc. Soc. exp. Biol. (N.Y.), 82, 514.

(1959). A.M.A. Arch. Neurol. Psychiat., 81, 55.

Jones, O. W. Jr., Ashton, D. M., and Wyngaarden, J. B. (1962). J. clin. Invest., 41, 1805.

Kalow, W. (1959). In Biochemistry of Human Genctics, Ciba Foundation Symposium, edited by G. E. W. Wolstenholme and C. M. O'Connor, p. 39. Churchill, London.

Kaser, H., Cottier, P., and Antener, I. (1962). J. Pediat., 61, 386.

Klatskin, G. (1961). Ann. Rev. Med., 12, 211.

Klein, R., Taylor, P., Papadatos, C., Laron, Z., Keele, D., Fortunato, J., Byers, C., and Billings, C. (1958). Proc. Soc. exp. Biol. (N.Y.), 98, 863.

Kupiecki, F. P., and Coon, M. J. (1957). J. biol. Chem., 229, 743.

La Du, B. N., Zannoni, V. G., Laster, L., and Seegmiller, J. E. (1958). Ibid., 230, 251.

Lane, M. R. (1961). J. Pediat., 58, 80.

Lasker, M., Enklewitz, M., and Lasker, G. W. (1936). Hum. Biol., 8, 243.

Lathe, G. H., and Walker, M. (1958). Biochem. J., 70, 705.

Lehmann, H., and Ryan, E. (1956). Lancet, 2, 124

Lepoutre. (1925). J. Urol. méd. chir., 20, 424.

Levin, B., Mackay, H. M. M., and Oberholzer, V. G. (1961). Arch. Dis. Childh., 36, 622.
Lewis, G. M., Stewart, K. M., and Spencer-Peet, J. (1962). Biochem. J., 84, 115 .

Lowe, C. U., Sokal, J. E., Mosovich, L. L., Sarcione, E. J., and Doray, B. H. (1962). Amer. J. Med., 33, 4.

Mackenzie, D. Y., and Woolf, L. I. (1959). Brit. med. J., 1, 90.

Maxwell, E. S., and Topper, Y. J. (1961). J. biol. Chem., 236, 1032.

McArdle. B. (1951). Clin. Sci., 10, 13.

McCance, R. A., Morrison, A. B., and Dent, C. E. (1955). Lancet, 1, 131.

McGirr, E. M. (1960). Brit. med. Bull., 16, 113.

- , and Hutchison, J. H. (1953). Lancet, 1, 1117.

McMurray, W. C., Mohyuddin, F., Rossiter, R. J., Rathbun, J. C., Valentine, G. H., Koegler, S. J., and Zarfas, D. E. (1962). Lancet, 1, 138.

Medes, G. (1932). Biochem. J., 26, 917.

- , Berglund, H., and Lohmann, A. (1927). Proc. Soc. exp. Biol (N.Y.), 25, 210.

Menkes, J. H., Hurst, P. L., and Craig, J. M. (1954). Pediatrics, 14, 462.

Mendel, G. (1901). Versuche über Pflanzenhybriden. Engelman, Leipzig.

Meulengracht, E. (1947). Quart. J. Med., 1683.

Mitoma, C., Auld, R. M., and Udenfriend, S. (1957). Proc. Soc. exp. Biol. (N.Y), 94, 634 .

Newton, W. A. Jr., and Bass, J. C. (1958). Amer. J. Dis. Child., 96, 501

Nikkila, E. A., Somersalo, O., Pitkanen, E., and Perheentupa, J. (1962). Metabolism, 11, 727.

Norton, P. M., Roitman, E., Snyderman, S. E., and Holt, L. E. Jr (1962). Lancet, 1, 26.

Rathbun, J. C. (1948). Amer. Dis. J. Child., 75, 822.

Rotor, A. B., Manahan, L., and Florentin, A. (1948). Acta med. philipp., 5, 37.

Russell, A., Levin, B., Oberholzer, V. G., and Sinclair, L. (1962). Lancet, 2, 699.

Salkowski, E., and Jastrowitz, M. (1892). Cent. med. Wissensch., 30, 337.

Schafer, I. A., Scriver, C. R., and Efron, M. L. (1962). Ne'w Engl. J. Med., 267, 51.

Schmid, R., and Hammaker, L. (1959). Ibid., 260, 1310.

(1960). In The Metabolic Basis of Inherited Disease, edited by J. B. Stanbury, J. B. Wyngaarden, and D. S. Fredrickson, pp. 226 and 939. McGraw-Hill, New York.

. and Hammaker, L. (1961). New Engl. J. Med., 264, 223. Biochem. J., 62, 34.

Schwartz, R., Ashmore, J., and Renold, A. E. (1957). Pediatrics, 19, 585 .

Schultz, A. L., Flink, E. B., Kennedy, B. J., and Zieve, L. (1957). $\frac{\widehat{C}}{\mathrm{O}}$ J. clin. Endocr., 17, 441.

Scott, E. M., and Griffith, I. V. (1959). Biochim. biophys. Acta (Amst.), 34, 584 .

Sidbury, J. B. Jr., Mason, J., Burns, W. B. Jr., and Ruebner, B. H. (1962). Bull. Johns Hopk. Hosp., 111, 157.

Sobel, E. H., Clark, L. C. Jr., Fox, R. P., and Robinow, M. (1953). Pediatrics, 11, 309.

Sokal, J. E., Lowe, C. U., Sarcione, E. J., Mosovich, L. L., and Doray, B. H. (1961). J. clin. Invest., 40, 364.

Sorensen, L. B. (1959). Metabolism, 8, 687 .
Sporn, M. B., Dingman, W., Defalco, A., and Davies, R. K. (1959). Nature (Lond.), 183, 1520.

Stanbury, J. B. (1961). Amer. J. clin. Nutr., 9, 669.

- , and Chapman, E. M. (1960). Lancet, 1, 1162.

_- and Hedge, A. N. (1950). J. clin. Endocr., 10, 1471 and McGirr, E. M. (1957). Amer. J. med., 22, 712.

Ohela, K., and Pitt-Rivers, R. (1955). J. clin. Endocr., 15, 54. Wyngaarden, J. B., and Fredrickson, D. S. (1960). The Metabolic Basis of Inherited Disease. McGraw-Hill, New York.

Touster, O. (1960). Fed. Proc., 19, 977.

Visakorpi, J. K. (1962). Lancet, 1, 1357.

Waldenström, J. (1937). Acta med. scand., suppl., 82.

(1957). Amer. $J$. Med., 22, 758.

Weijers, H. A., Kamer, J. H. van, Dicke, W. K., and Ijsseling, J. (1961). Acta paediat. (Uppsala), 50, 55.

Westall, R. G. (1961). Biochem. J., 77, 135.

-, Dancis, J., and Miller, S. (1957). Amer. J. Dis. Child., 94, 571. Фृ

Wilkins, L., Lewis, R. A., Klein, R., and Rosemberg. E. (1950). Bull. Johns Hopk. Hosp., 86, 249.

Wolf, R. L. Pizette, M., Richman, A., Dreiling, D. A., Jacobs, W., Fernandez, O., and Popper, H. (1960). Amer. J. Med., 28, 32. Wyngaarden, J. B. (1960). Bull. N.Y. Acad. Med., 35, 419. 